\title{
Simulating the Midlatitude Atmospheric Circulation: What Might We Gain From High-Resolution Modeling of Air-Sea Interactions?
}

\author{
A. Czaja ${ }^{1}(\mathbb{D})$ C. Frankignoul $^{2} \cdot$ S. Minobe $^{3} \cdot$ B. Vannière ${ }^{4}$
}

Published online: 4 November 2019

(C) The Author(s) 2019

\begin{abstract}
Purpose of Review To provide a snapshot of the current research on the oceanic forcing of the atmospheric circulation in midlatitudes and a concise update on previous review papers.

Recent Findings Atmospheric models used for seasonal and longer timescales predictions are starting to resolve motions so far only studied in conjunction with weather forecasts. These phenomena have horizontal scales of $\sim 10-100 \mathrm{~km}$ which coincide with energetic scales in the ocean circulation. Evidence has been presented that, as a result of this matching of scale, oceanic forcing of the atmosphere was enhanced in models with 10-100 km grid size, especially at upper tropospheric levels. The robustness of these results and their underlying mechanisms are however unclear.

Summary Despite indications that higher resolution atmospheric models respond more strongly to sea surface temperature anomalies, their responses are still generally weaker than those estimated empirically from observations. Coarse atmospheric models (grid size greater than $100 \mathrm{~km}$ ) will miss important signals arising from future changes in ocean circulation unless new parameterizations are developed.
\end{abstract}

Keywords Ocean-atmosphere interactions $\cdot$ High-resolution climate modeling $\cdot$ Midlatitude climate dynamics $\cdot$ Sea surface temperature anomalies · This article is part of the Topical Collection on Mid-latitude Processes and Climate Change

\section{Introduction}

Fluctuations in sea surface temperature (SST) in the extratropics have been documented since the 1970s. The available data at the time suggested that their spatial scale was large (i.e., on the scale of ocean basins), that their amplitude was on the order of $1 \mathrm{~K}$, and that they were quite persistent (at least several months, i.e., much longer than the timescale associated with the weather). This led early investigations to hypothesize

This article is part of the Topical Collection on Mid-latitude Processes and Climate Change

A. Czaja

a.czaja@imperial.ac.uk

1 Department of Physics, Imperial College London, Prince Consort Road, London SW7 2AZ, UK

2 Sorbonne Université, IRD/MNHN/CNRS, LOCEAN, 4 Place Jussieu, 75005 Paris, France

3 Faculty of Science, Hokkaido University, Sapporo, Japan

4 National Centre for Atmospheric Science, Department of Meteorology, University of Reading, Reading, UK that they exerted a significant impact on the extra-tropical atmospheric circulation, possibly enhancing predictive skill on weather, seasonal, and longer climate timescales.

As discussed in the reviews written on this issue since then by Frankignoul, Kushnir et al., Robinson, and Kwon et al. [1-4], evidence for a large impact of the extra-tropical SST anomalies on the atmospheric circulation had not been found. Rather, emphasis had been put on the fact that large-scale extra-tropical SST anomalies are forced by modes of atmospheric variability such as the North Atlantic Oscillation (NAO) and the Pacific North American pattern (PNA), and that the upper ocean provides a weak feedback on these modes. Large or weak refers here, as in [2], to whether the oceanic forcing, measured for example by the SST-induced geopotential height anomaly, is smaller or greater than that produced internally by the atmosphere. This quantification requires specifying a timescale since atmospheric spectra tend to be white and so the internal variability decreases with time averaging. Winter-towinter changes in geopotential height of $50 \mathrm{~m}$ at upper levels are not uncommon so this number is taken in the following as a reference value. Quantifying the strength of the SST forcing also requires specifying a realistic amplitude for SST anomaly 
as there is little point in normalizing an atmospheric response by $1 \mathrm{~K}$ in a region where such SST amplitude is rarely reached or frequently exceeded. Hence, in this review, we will quote numbers as typical maximum geopotential height anomaly per maximum SST anomaly.

The purpose of this review is to provide a snapshot of the current state of research by offering a concise update on the review by Kushnir [2]. A central theme is to assess whether the "small oceanic forcing" regime suggested in that review (a number of $20 \mathrm{~m}$ at $500 \mathrm{hPa}$ for a 1-K SST anomaly was quoted as a typical value) is relevant or not to the real world. This question is important in the context of climate change because the ocean circulation, especially in mid to high latitudes, is expected to respond significantly to increasing concentration of greenhouse gases and aerosols [5], and climate models need to be able to simulate accurately the associated impact on the weather patterns in midlatitudes and globally. Studies reviewed at the time in [2] used Atmospheric General Circulation Models (hereafter AGCMs) resolving adequately dynamics at the atmospheric deformation radius $\operatorname{scale}^{1}(\sim$ $1000 \mathrm{~km}$ ) but not at the $10-100 \mathrm{~km}$ scale, which motivates a re-examination of this issue. Note that a focus is put here on ocean forcing at upper tropospheric levels because this is where teleconnection patterns such as the NAO and PNA are set [6]. We also focus on wintertime as this is the time of year when such patterns are the strongest, as are midlatitudes air-sea interactions.

Several recent results suggest that the "small oceanic forcing" regime might not be relevant to the real world. It is now known that AGCMs and the coupled seasonal forecasting systems based on them exhibit less predictability than nature in midlatitudes; for example, the correlation between predicted and observed NAO index is higher for the real atmosphere than for the atmosphere of the forecasting system, despite a realistic simulation of the noise level (e.g., [7-9]). This points to a lack of signal or sensitivity which could be related to an underestimation of boundary forcing in the current generation of atmospheric models, possibly from the midlatitude ocean. Additional support for this claim is that AGCMs are not able to simulate, even when forced with observed SST anomalies, the pronounced multidecadal variability displayed by the Jet Stream in the North Atlantic over the twentieth century [10]. In addition, it is clear that spatial fluctuations in SST on scales much smaller than ocean basins but closer to the oceanic deformation radius $(10-100 \mathrm{~km})$ affect the lower atmosphere (see for example the review in [11]). New studies start revealing mechanisms by which this oceanic variability might be "communicated upward" to the upper levels of the atmosphere if AGCMs have enough spatial resolution to see these features (e.g., [12-19]). Finally, and this might be the most

\footnotetext{
${ }^{1}$ For the atmosphere and the ocean, the deformation radius is the horizontal scale at which rotation effects become as important as buoyancy effects.
}

direct evidence for a stronger oceanic forcing than has previously been acknowledged and reviewed in [2], recent estimates of its strength in reanalysis data using statistical techniques are sometimes in excess of $60 \mathrm{~m} / 0.5 \mathrm{~K}$ for geopotential height anomalies at upper levels (e.g., [20-22]).

We are rapidly moving away from AGCMs with horizontal resolution of a few $100 \mathrm{~km}$ (hereafter low res) toward AGCMs with a few tens of kilometers resolution (hereafter high-res). We refer throughout this paper to the "mesoscale" as the range of horizontal scale within $10-100 \mathrm{~km}$ which is starting to be resolved in global coupled seasonal forecasting systems but not yet in global coupled climate models used for climate change predictions. This corresponds to a dynamical regime where, in the extra-tropics, the Rossby number ${ }^{2}$ is on the order of unity in the atmosphere $([23,24]$, in agreement with their "advective regime"), but is smaller than unity in the ocean [25].

The review is structured as follows. In the "What Are the Atmospheric Motions and the Climatic Features Which Improve When Increasing an AGCM Resolution From 100 to $\sim 10 \mathrm{~km}$ in Midlatitudes?" section, relevant atmospheric features affected by spatial resolution are reviewed, while the "How Do the Extra-Tropical Oceans Affect the Storm Track/Jet Stream System?" section discusses mechanisms by which the ocean circulation might affect these features. The magnitude of the oceanic forcing is critically reviewed in the "Observational Constraints on the Extra-Tropical Oceanic Forcing" section, while the "Implications for Climate Change Predictions" section synthesizes the implications of all preceding sections for climate change predictions. Conclusions, suggestions for future research, and a tentative answer to the question posed in this review's title are offered in the "Conclusion" section.

\section{What Are the Atmospheric Motions and the Climatic Features Which Improve When Increasing an AGCM Resolution From 100 to $10 \mathrm{~km}$ in Midlatitudes?}

Increasing atmospheric model resolution from low res to high res has been shown to improve the representation of largescale circulations in the midlatitudes: cyclones [26], the location and frequency of occurrence of blockings $[26,27]$, and the non-Gaussian nature of North-Atlantic weather regimes [28].

In addition, kinetic energy spectra have been used to show that additional contributions from smaller scales emerge when the resolution of AGCMs is increased [29-31]. This has led to the notion of an "effective resolution," defined as the

\footnotetext{
${ }^{2}$ The Rossby number is a measure of the relative strength of inertia and Coriolis force.
} 
wavenumber beyond which the slope of the spectrum steepens from $-5 / 3$. Klaver [31] demonstrated, based on an ensemble of AGCMs spanning a large range of resolutions, that it is on average 3 times the size of the atmospheric grid cell. Thus, even a $25-\mathrm{km}$ AGCM might only resolve the end of the mesoscale spectrum $(\sim 100 \mathrm{~km})$.

Midlatitude transient eddies in the atmosphere are shaped by the quasi-stationary flow but also affect it in return (e.g., [32]). The question naturally arises to which extent the increase in horizontal resolution could enhance this feedback. Held and Phillipps [33] suggested that resolution has little impact on eddy heat transport because, if the eddy heat flux is underestimated, a self-correcting feedback comes into play (the temperature gradient increases). This is in contrast with the eddy momentum flux which the model has little incentive to correct when it is underpredicted. Orlanski [34] demonstrated that the eddy momentum flux by synoptic eddies plays a different role on the mean climate in different frequency bands. Intermediate-frequency eddies (5-12 days) always flux momentum poleward, but a bifurcation exists for very high frequency eddies (1-5 days): eddy momentum is fluxed equatorward or poleward depending on whether their kinetic energy is high or low, respectively ${ }^{3}$. For example, the GFDL AM2 M90 model (at a $1^{\circ}$ resolution) was shown to simulate correctly the momentum flux and energy of intermediatefrequency eddies but not those of very high frequency eddies (the variance of the latter was underestimated by $\sim 20 \%$ compared with ERA40 reanalysis [34]). These results have important implications for the oceanic forcing of the storm track/Jet Stream system on both the atmospheric and oceanic deformation radius scales which we will address in the "How Do the Extra-Tropical Oceans Affect the Storm Track/Jet Stream System?" section.

Despite the argument mentioned in [33], recent work has also suggested a non-negligible increase of the eddy heat flux ( $\mathrm{v}^{\prime} \mathrm{T}^{\prime}$, where $\mathrm{v}^{\prime}$ and $\mathrm{T}^{\prime}$ refer respectively to the eddy meridional velocity and temperature) over western boundary currents of the ocean like the Gulf Stream or Kuroshio that could be caused by resolution. Willison et al. [35] found that $\mathrm{v}^{\prime} \mathrm{T}^{\prime}$ was increased by approximately $24 \%$ in the North-Atlantic when the resolution of their limited area model (LAM) was increased from 120 to $20 \mathrm{~km}$. Smirnov et al. [14] found convincing evidence that the diabatic heating resulting from an anomalous SST in the Oyashio extension was balanced by mean flow cold advection at low resolution, but by an increased eddy heat flux in the high-resolution (such dynamics are further discussed in the "How Do the Extra-Tropical

\footnotetext{
${ }^{3}$ Note also that the eddy anisotropy is different for low and high frequency eddies. This is very important because derivatives of $\mathrm{v}^{\prime 2}-\mathrm{u}^{\prime 2}$ dominate in the feedback on stationary waves ( $\mathrm{u}^{\prime}$ and $\mathrm{v}^{\prime}$ denoting the zonal and meridional eddy velocity, respectively).
}

Oceans Affect the Storm Track/Jet Stream System?" section). However, each of the two results comes with its own caveats. LAM studies, as used by Willison et al. [35], do not have a global energy constraint and as such might miss important feedbacks rectifying the mean state on which eddies develop. Conversely, the mean midlatitude atmospheric circulation of global AGCMs, as used in [14], is sensitive to resolution, though not always in the same way, and this might drive different storm track responses to a given anomalous heating $[36,37]$. This sensitivity is illustrated in Fig. 1 for the wintertime mean zonal wind at upper levels in six state-of-the-art AGCMs. In Fig. 1a, we display in color the difference in this variable between a high- and a low-resolution version of the model (all models were forced with the same SST so as to emphasize changes arising from resolution as opposed to oceanic forcing, see [38]), superimposed on the high-resolution climatology (black contours; the dots indicate the $95 \%$ significance level). Changes on the order of 5-10 m/s (about 1020\%) are produced when increasing the resolution, sometimes inducing a poleward shift of the jet (e.g., Fig. 1a, top panel in the western Pacific), sometimes a southward shift (Fig.1a, bottom panel in the western Pacific). Indeed, as Fig. 1b quantifies, the larger the increase in resolution, the larger the change in the time mean zonal winds (a few $\mathrm{m} / \mathrm{s}$ for each doubling of the resolution). Models for which the ratio $\mathrm{R}$ of resolution (high res/low res) is close to unity also display the least significant changes in panel (a), as expected. It is not clear however that even significant changes systematically bring the models closer to observations as both positive and negative changes in biases are found at the smallest values of $R(\sim 0.2)$ in Fig. 1c.

Cold and warm fronts associated with extra-tropical cyclones have typically a width of $\sim 100 \mathrm{~km}$ and are characterized by strong uplift where most of the diabatic heating occurs. Willison et al. [35] convincingly showed that low-res models are unable to represent the narrow extent of the diabatic heating. Because the diagnostic relationship between heating and vertical motion in midlatitudes involves the horizontal Laplacian of the heating and thus filters out large spatial scales (the so-called "omega equation," see [39]), this also explains why the vertical velocity field is misrepresented in low-res models [40]. This is an issue because, as AGCMs become able to represent better the narrow nature of ascending motion, the compensating subsidence becomes more spread out and non-local. As a result, net upward motion can occur in the mean over western boundary currents (e.g., [41]), possibly acting as a vorticity forcing at upper levels [42]. The narrowness of the heating field also strongly impacts the covariance $T$ ' $\mathrm{Q}^{\prime}$ (where $\mathrm{Q}^{\prime}$ is the eddy diabatic heating) which is a source term of eddy potential energy in the Lorenz energy cycle $[16$, 35]. In their simulation, Willison et al. [35] showed that this term increased by $\sim 60 \%$ in the storm track region between low res and high res. 

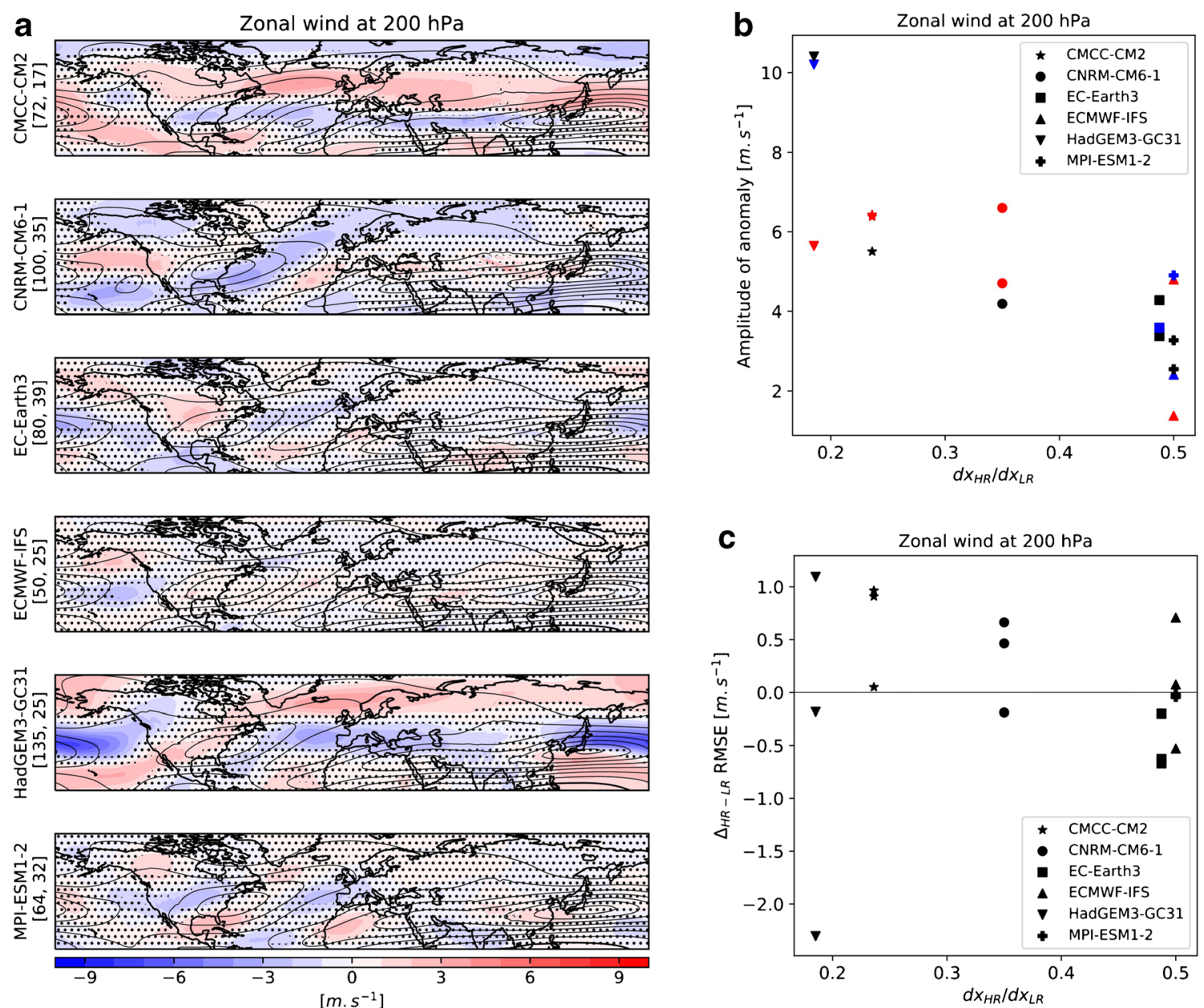

Fig. 1 a Difference in long time mean zonal wind between the high and low resolution (color) of six AGCMs forced with the same time varying SST. The high-res climatology is superimposed in black contours ( $\mathrm{ci}=10$ $\mathrm{m} / \mathrm{s}$ ). Dots indicate where the change is not significant at the $95 \%$ confidence level. b Regional changes in jet strength (in $\mathrm{m} / \mathrm{s}$ ) and position as a function of the increase in resolution (i.e., the ratio of gridsize hi-res/lowres) for the Atlantic, Western, and Eastern Pacific sector (i.e., 3 points per model). Blue indicates equatorward shift, red poleward shift, and black no

The conditional symmetric instability (CSI) is a type of moist instability which has received particular attention as it is the only instability occurring in the mesoscale range in the midlatitudes ${ }^{4}$ [43-46]. It develops in regions of strong temperature gradient and large windshear, such as fronts. The occurrence of CSI can give rise to deep cross-frontal slantwise convection. This situation is difficult to observe as frontal regions are often close to neutrality ${ }^{5}$ and the induced motion is difficult to distinguish from circulation induced by frontogenesis (see the review by Schultz and Schumacher [47] for a full discussion). Nevertheless, the slantwise moist instability

\footnotetext{
${ }^{4}$ CSI does not select a spatial scale but it occurs on the scale of the frontal updraft.

${ }^{5}$ That is, parcels ascending in a frontal region have a buoyancy close to that of the surrounding air.
}

shift. $\mathbf{c}$ Change in the rms error (in $\mathrm{m} / \mathrm{s}$ ) computed, for each basin, from a comparison with the ERA5 climatology. The approximate resolution of the models at $50 \mathrm{~N}$ is given in bracket (in $\mathrm{km}$ ) for their high- and low-res versions in panel (a). All fields are for wintertime mean at $200 \mathrm{hPa}$ over 1950-2014 except for (c) where the 1980-2014 mean is used to allow comparison with ERA5. More information about the simulations can be found in [38]

or neutrality means that the existing frontal circulation can intensify rapidly. Czaja and Blunt [48] used the moist Richardson number (Ri) as an indicator of CSI and found that situations favorable to slantwise convection (i.e., $0<\mathrm{Ri}<1$ ) were three times more frequent than for upright convection $(\mathrm{Ri}=0)$ over the Gulf Stream. Similar qualitative results were obtained by Glinton et al. [49] in their analysis of slantwise and standard convective available potential energy (SCAPE and CAPE, respectively) over the North Atlantic. Resolution of at least $25 \mathrm{~km}$ has been suggested to represent CSI but increasing resolution allowed to simulate additional rain bands ([50] - the importance of vertical resolution must also be mentioned, even if only just briefly here, as the aspect ratio of the motion becomes closer to unity in frontal circulations). There have been several attempts at parameterizing slantwise convection (e.g., [51, 52]) which have been shown to produce a 
more realistic organization of line convection and precipitation [53].

In summary, the eddy feedback on the mean flow, poleward heat fluxes, and frontal structures have all shown to be strongly affected by an increase in horizontal resolution in recent studies. Although we have emphasized positive results brought about by the increase in resolution, it must be kept in mind that increasing resolution can also sometimes degrade the performance of not only an AGCM (as Fig. 1c suggests) but also a coupled system. For example, although the GloSea5 forecasting system of the UK Met Office showed significant predictive skill of the NAO with the atmospheric component run at $60 \mathrm{~km}$ [7], that skill was found to decrease significantly (a factor of two in terms of NAO index correlation) when run at $25 \mathrm{~km}$ [54].

\section{How Do the Extra-Tropical Oceans Affect the Storm Track/Jet Stream System?}

\section{Large-Scale Oceanic Forcing}

The forcing of the atmosphere by the extra-tropical ocean on the scale of the atmospheric deformation radius $(\sim 1000 \mathrm{~km})$ was reviewed by Kushnir et al. [2]. This study identified two mechanisms, the "linear baroclinic response" and the "storm track response." The first, according to the scale analysis of [55], is expected to cause descent over warm SST anomalies, as well as a surface low/upper level high geopotential height anomaly. This prediction is not expected to hold when the total horizontal wave number $\left(k^{2}+l^{2}\right.$ where $k$ and $l$ are the zonal and meridional wavenumbers, respectively) is large, which can occur either for oceanic fronts (one of $k$ or $l$ is large) or eddies (both $k$ and $l$ are large). If the linear baroclinic response causes upper level divergence or convergence, further perturbations can propagate to other regions via waves, causing remote responses to SST anomalies. A recent example is provided by Sato et al. [56] who suggested that the meridional shifts of the Gulf Stream cause linear Rossby wave responses in early winter over Europe, based on experiments with a linearized atmospheric model.

In practice, the ultimate fate of the linear baroclinic response is mediated by the interaction between the mean circulation and the eddies [57], and this is the second mechanism (storm track response) discussed by Kushnir et al. [2]. Often, but not in all AGCM studies, the upper level geopotential height anomaly is reinforced by this interaction, while the surface low weakens, leading, at equilibrium, to a column of the same sign geopotential height anomalies increasing with height in magnitude. Since that review was published, several studies have highlighted the role that mean SST structures play in shaping the North Atlantic eddy-driven jet [58] and blocking [59]. The latter two studies analyzed 20-year experiments using observed SSTs as well as smoothed SSTs in an
AGCM, but different smoothing experiments using different AGCMs also reported storm track changes $[60,61]$. It is important to emphasize that the prevailing paradigm is that the storm track response is well captured by dry quasi-geostrophic dynamics (hereafter QG, a theoretical framework adequate for motions of spatial scale comparable with the atmospheric deformation radius), since even very low-resolution QG models have been able to reproduce the salient features of the eddy mean flow feedback generated by low-res AGCMs $[62,63]$. Nevertheless, as briefly reviewed in the "What Are the Atmospheric Motions and the Climatic Features Which Improve When Increasing an AGCM Resolution From 100 to $\sim 10 \mathrm{~km}$ in Midlatitudes?" section, more recent analyses of AGCMs show an important role for eddies whose dynamics is not captured by QG dynamics (the very high frequency eddies discussed in [34]), as well as an important role for latent heat release. Thus, this paradigm might need to be revisited. This is further underscored by the strong non-linearity seen in recent experiments (e.g., $[64,65])$, while the QG paradigm in $[62,63]$ relies on linear storm track dynamics.

Another important line of research since the review by Kushnir et al. [2] has been to suggest that SST gradients are instrumental in setting cyclogenesis through diabatic effects in the lower troposphere [66-69]. Nevertheless, and although these studies have been phrased in the context of "oceanic frontal zones," the scales considered are comparable with the atmospheric deformation radius and so these studies may still be of too coarse resolution to represent oceanic fronts accurately. For example, in the study by Nakamura et al. [67], and more recently in [70], the "frontal" region is represented by $6(8)$ grid points at $150(180) \mathrm{km}$ resolution, i.e., a width of $900(1440) \mathrm{km}$. The impact of low-level baroclinicity ${ }^{6}$ on cyclogenesis is typically evaluated using the Eady growth rate [71]. Piazza et al [60] (see also [72] in the context of sensitivity to ocean model resolution) showed that SST smoothing and non-smoothing experiments for the North Atlantic exhibited a substantial difference in this quantity associated with the horizontal air-temperature gradient, whereas Kuwano-Yoshida and Minobe [73] showed that it does not change much in their smoothing experiment over the Kuroshio region because of the compensating effect between the horizontal (destabilizing) and vertical (stabilizing) temperature gradients.

Surface latent heat fluxes and latent heat release can also contribute to the maintaining of atmospheric baroclinicity and the localization of storm tracks [71, 74]. A series of original studies by Ma et al. $[15,16]$ recently argued that the oceanic mesoscale eddy field modulates the amount of heat and moisture fluxed into the marine boundary layer as a little bit more heat is given to the atmosphere over a warm ocean eddy than

\footnotetext{
${ }^{6}$ Baroclinicity is taken here to mean horizontal temperature gradients.
} 
is lost over a cold ocean eddy (this effect involves both the non-linearity of the Clausius-Clapeyron relationship and the presence of enhanced winds over warmer waters - see the review by Small et al. [11]). Although this effect involves the oceanic mesoscale $(10-100 \mathrm{~km})$, it is spatially averaged over the larger scale of the cold and warm sectors of cyclones and thus does not represent a direct oceanic forcing on the scale of the oceanic eddies. Rather, it acts to shift the oceanic sources of heat and moisture a little bit poleward as ocean eddies typically develop over a region separating warm (further equatorward) and cold waters (further poleward). Ma et al. [16] showed in a LAM with a 27-km resolution that this induced a poleward shift of the North Pacific storm track in response but, interestingly, this did not happen when the resolution was decreased to $\sim 160 \mathrm{~km}$ as the model was then not able to "see" the oceanic mesoscale. This striking result is further illustrated in Fig. 2. In an idealized experiment, Foussard et al. [19] were able to simulate the poleward shift of the storm track by simply adding a large-scale heat and moisture source centered on an oceanic front rather than explicitly representing the oceanic eddies developing on that front. An alternative explanation of these results is provided by Tamarin and Kaspi [75] who showed how increasing latent heating in cyclones, as a result of a stronger surface heat source over the ocean, can also contribute to poleward migration of the storm tracks.

\section{Small-Scale Oceanic Forcing}

The forcing of the storm track/Jet Stream system at the scale of the oceanic deformation radius (10-100 $\mathrm{km}$ in midlatitudes) is only beginning to be investigated. It is well known from earlier studies that SST features on these scales are important to simulate the structure and movement of cyclones (e.g., [76, 77]), their deepening rate (e.g., [78, 79]), and maybe even the frequency of lightning $[80,81]$. Nevertheless, the computational challenge of scaling up these results (weather) to long global simulations (climate), or ensemble of these, is very significant $[82,83]$ and only begins to be addressed in atmosphere-only set-ups (e.g., [84]).

A few stimulating ideas linking weather and climate are worth mentioning. First, the midlatitude ocean and its energetic mesoscale structures affect the rainfall distribution because the latter largely reflects the strength and movement of weather fronts [85] whose spatial scales match those of the oceanic mesoscale. The basic idea is illustrated in Fig. 3, which displays various possible configurations of oceanic and atmospheric temperature fronts. In some cases (Fig. 3b), warm
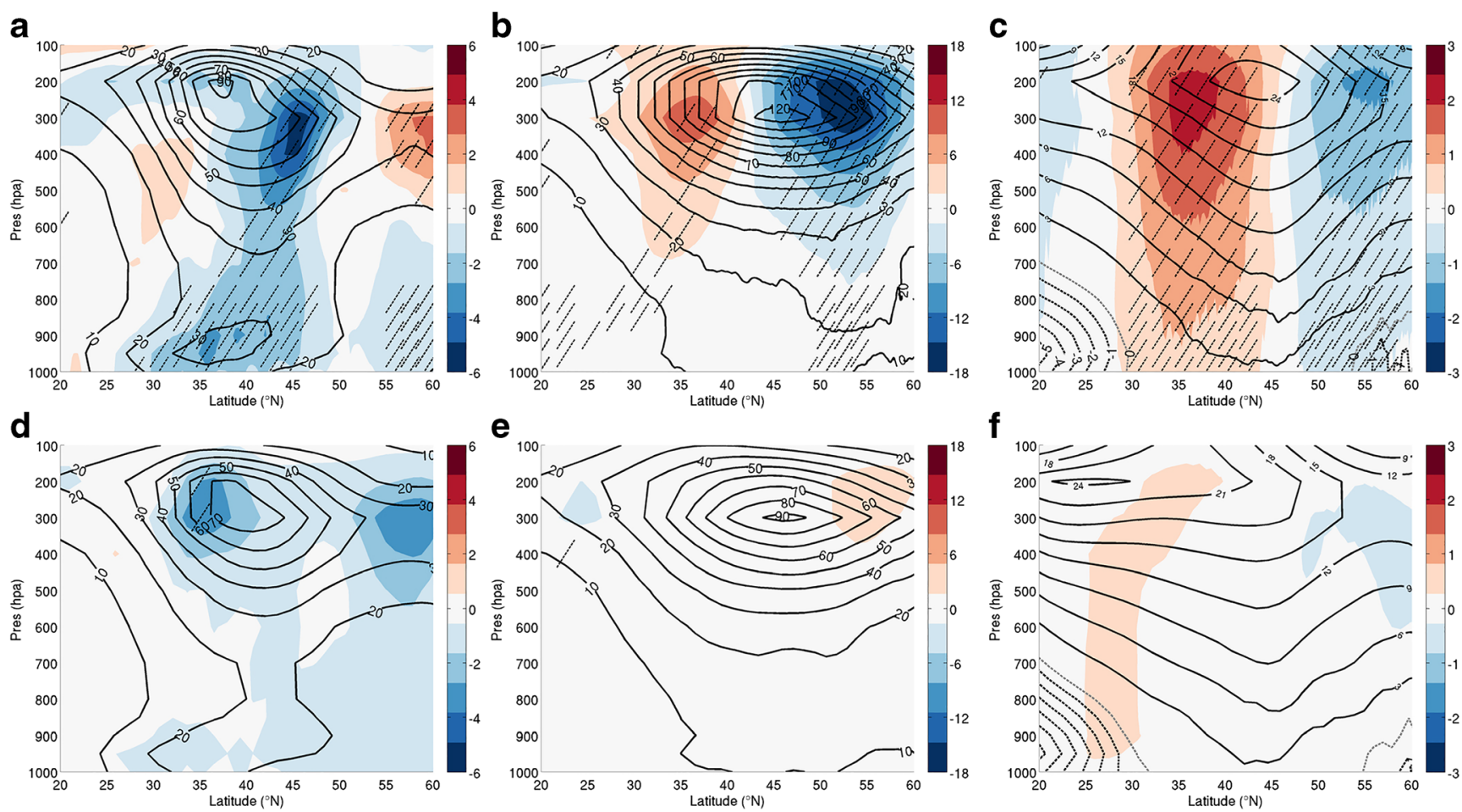

Fig. 2 a Vertical and latitudinal profile of winter mean (contours) storm track ( $\mathrm{v}^{\prime 2}$ where $\mathrm{v}^{\prime}$ is eddy meridional velocity) in the Western Pacific in a control simulation (CTRL) with realistic SSTs and 27-km resolution, and change in that quantity (color, in $\mathrm{m}^{2} / \mathrm{s}^{2}$ ) in an experiment where mesoscale SST features were removed (FILT), i.e., FILT-CTRL is plotted. b Same as (a) but for the Eastern Pacific. c Same as (b) but for the zonally

averaged wind instead of $\mathrm{v}^{\prime 2}$, in units of $\mathrm{m} / \mathrm{s}$. Panels $(\mathbf{d}),(\mathbf{e})$, and (f) are the exact counterparts to panels (a), (b), and (c) but in a simulation where the horizontal resolution was degraded to $162 \mathrm{~km}$. Note that in this case, no significant signals (hatched regions) are seen in the FILT-CTRL plots. Reproduced from [16]. CAmerican Meteorological Society. Used with permission 

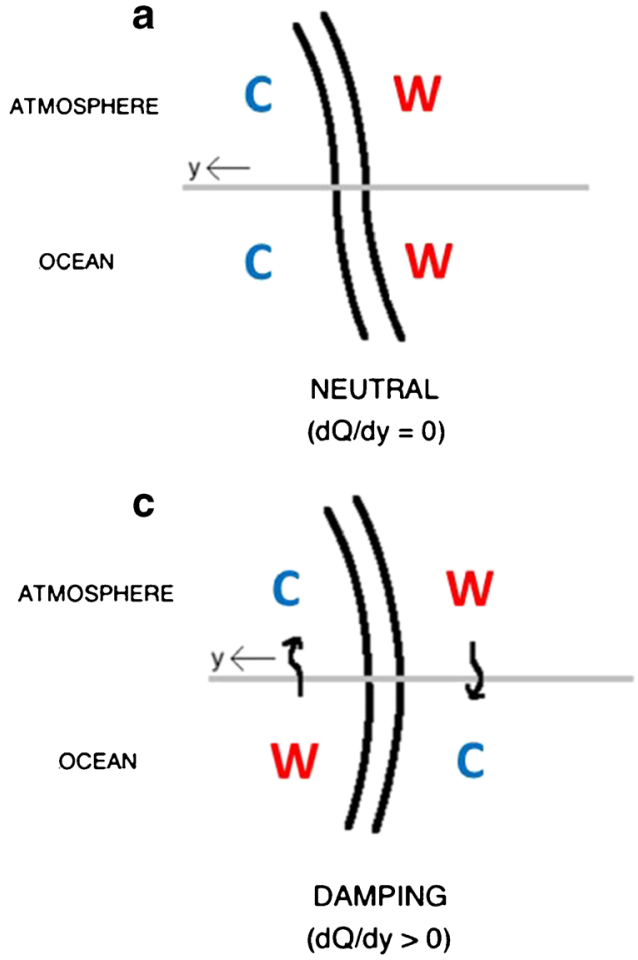

Fig. 3 Thermal damping and strengthening of atmospheric fronts. The relative orientation of oceanic and atmospheric fronts is indicated by the position of isentropic surfaces (black lines), with the warm and cold regions highlighted by the letters $\mathrm{W}$ and $\mathrm{C}$ respectively. The sensible surface heat flux $Q$, positive downward, is indicated by wavy arrows. Warm air over warm water and cold air over cold water in panel (a) is a thermally equilibrated situation $(Q=0)$. This contrasts with panel (b)

(cold) air lies above even warmer (colder) ocean temperature, and the resulting air-sea heat flux acts to strengthen the frontal circulation and the associated rainfall. Conversely, when warm (cold) air lies above cold (warm) water, as in Fig. 3c, the frontal circulation is weakened by the horizontal gradient in air-sea heat flux. Parfitt et al. [86] showed that these arguments could explain how the increase in SST resolution used in the ERA-interim reanalysis after 2001 caused an increase in precipitation by up to $30 \%$ in the North Atlantic in wintertime.

Another line of thought is that the more zonal or more tilted position of the Jet Stream is affected by the number of low potential vorticity $(\mathrm{PV})^{7}$ air masses brought to upper levels in the warm conveyor belt of cyclones. It was shown by Pfahl et al. [87] that 30 to $45 \%$ of air masses involved in blocking episodes in the North Atlantic underwent prior diabatic modification of their PV as they ascended from lower to upper levels of the troposphere. Here again oceanic mesoscale structures are likely key players in setting the production of these low PV air masses through air-sea interactions in the cold

\footnotetext{
${ }^{7} \mathrm{PV}$ is a scalar which contains dynamical and thermodynamical information about the atmosphere. Low values of PV are typically associated with anticyclonic flows and are produced above a region of heating.
}

b

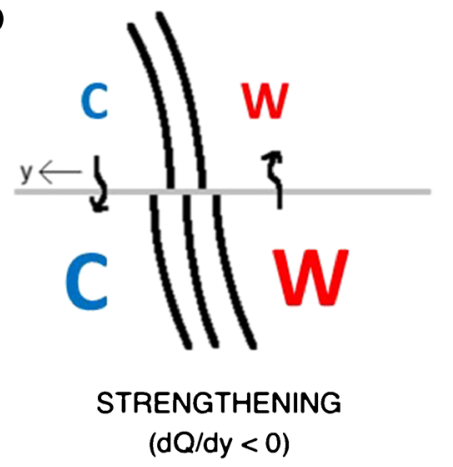

d

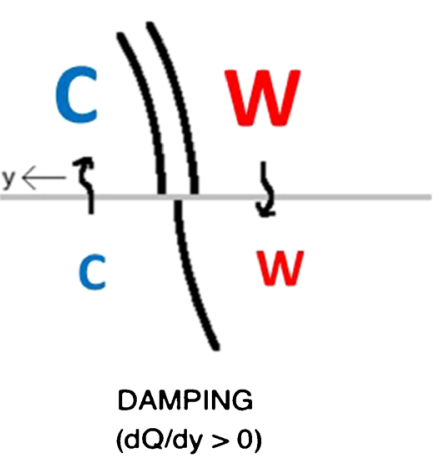

where very warm (cold) ocean waters are found over warm (cold) air masses, leading to a horizontal gradient in $Q$ and a strengthening of the frontal circulation (thermally direct, i.e., with warm air rising and cold air sinking). Panels (c) and (d) illustrate alternative situations where the horizontal heat flux gradient is reversed and the circulation weakened. Adapted from [17]

sector of cyclones [69], and possibly in enhancing the ascent from low levels through a form of CSI (the "What Are the Atmospheric Motions and the Climatic Features Which Improve When Increasing an AGCM Resolution From 100 to $~ 10 \mathrm{~km}$ in Midlatitudes?" section; [18]).

Finally, we note that the energy threshold emphasized in [34] and briefly discussed in the "What Are the Atmospheric Motions and the Climatic Features Which Improve When Increasing an AGCM Resolution From $\sim 100$ to $\sim 10 \mathrm{~km}$ in Midlatitudes?" section in relation to momentum fluxes by very high frequency eddies is also likely to be affected by air-sea interactions on the scale of the oceanic deformation radius. Indeed, Ma et al. [16] showed that the presence of mesoscale oceanic features in SST enhances the production of eddy potential energy (the $\mathrm{T}^{\prime} \mathrm{Q}^{\prime}$ term introduced in the "What Are the Atmospheric Motions and the Climatic Features Which Improve When Increasing an AGCM Resolution From $\sim 100$ to $\sim 10 \mathrm{~km}$ in Midlatitudes?" section), as well as the conversion of that energy to eddy kinetic energy (the $\mathrm{w}^{\prime} \mathrm{T}^{\prime}$ term in the Lorenz cycle, where $\mathrm{w}^{\prime}$ is perturbation vertical velocity). These two processes contribute constructively to overall enhance the kinetic energy of the eddies and thus, from the arguments in [34], to alter the momentum fluxes by synoptic waves. 


\section{Observational Constraints on the Extra-Tropical Oceanic Forcing}

\section{Observational Estimates of the Response of the Atmosphere to SST Anomalies}

The atmospheric response to extra-tropical SST anomalies has been estimated from their relation to atmospheric fields lagging by more than atmospheric persistence, but less than SST persistence. The large-scale SST anomaly modes are fairly well observed since the twentieth century, and their impact has been extensively investigated since earlier studies by Ratcliffe and Murray [88], Palmer and Sun [89], and Czaja and Frankignoul $[90,91]$. On the other hand, high SST resolution is needed to resolve SST anomalies associated with oceanic frontal variability and mesoscale eddies. A (nominal) $14^{\circ}$ resolution SST product is available since 1982 [92], but higher resolution only since 2005. Likewise, satellite observations of sea level only allow to link these features to ocean dynamics from 1992 onwards. Limited SST resolution is unlikely to substantially degrade the large-scale response to oceanic frontal variability in atmospheric reanalyses, as the tropospheric state is strongly constrained by observations, but the marine atmospheric boundary layer is poorly constrained, and local frontal impacts, including surface heat flux, surface-wind convergence, and cloudiness, are only well represented if the SST resolution is very high [93].

In the North Pacific, recent studies have focused on the cold season atmospheric response to the variability of the western boundary current extensions. Using the maximum monthly meridional SST gradient to locate the Oyashio Extension (OE) front in $1 / 4^{\circ}$ SST data, Frankignoul et al. [20] found that a northward shift of the OE was followed by a positive phase of the North Pacific Oscillation (NPO) with a northern lobe amplitude reaching $-35 \mathrm{~m}$ at $250 \mathrm{hPa}$ (SLP of$2 \mathrm{hPa}$ ) for a $0.45-\mathrm{K} \mathrm{SST}$ anomaly, stronger in fall and winter and when the front is displaced southward. Using a $1^{\circ}$ resolution SST product to slightly extend the analysis period, Révelard et al. [22] found a smaller NPO response (-30 $\mathrm{m} / 0.8 \mathrm{~K}$ ) during fall, but a large one in late winter ( -60 to $80 \mathrm{~m}$ at $250 \mathrm{hPa}$, SLP of $-5.5 \mathrm{hPa} / 0.5 \mathrm{~K}$ ). The corresponding SST and geopotential height anomaly at $300 \mathrm{hPa}$ are shown in Fig. 4. There is some uncertainty in the estimated magnitudes, a point to which we return below, as they depend on an assumed 2-month response time to SST forcing (for monthly averages to reach full amplitude). This choice is roughly consistent with the 20-30 days needed to reach maximum amplitude in the observational analysis of $[94,95]$ and in highresolution simulations $[14,64]$. It also agrees with the 2month response time for monthly averages in AGCM studies (e.g., $[14,96])$, and the 2 to 3 -month lag seen in the maximum co-variability between SST and large-scale atmospheric anomalies. To estimate the response to the OE fluctuations in 1959-2006, Taguchi et al. [21] used the SST averaged in the subarctic frontal zone as OE index. They found that a frontal zone warming in November was followed by a strong strengthening of the Aleutian low $(-80 \mathrm{~m},-4 \mathrm{hPa} / \mathrm{K})$ in January, but a smaller opposite response in February.

The Kuroshio Extension (KE) variability also influences the atmosphere in the cold season by modulating local ascending motions and shifting the zone of maximum baroclinicity (see the "How Do the Extra-Tropical Oceans Affect the Storm Track/Jet Stream System?" section), but in an asymmetric way, as the estimated response reaches $70 \mathrm{~m} / 0.7 \mathrm{~K}$ at $250 \mathrm{hPa}$ when the KE is in a stable (northerly) state, but is not significant in the unstable (southerly) state [97]. Wills and Thompson [95] used daily winter data and showed that a warm SST in the Kuroshio-Oyashio extension (KOE) region precedes a surface intensified low slightly downstream, which only reaches about $-12 \mathrm{~m}$ at $1000 \mathrm{hPa} / 0.7 \mathrm{~K}$ after 30 days. Further empirical evidence for a direct relationship between the Kuroshio's large meander south of Japan and storm tracks and regional precipitation was obtained by Nakamura et al. [98].

In the North Atlantic, earlier analyses showed that a basinscale "horseshoe" SST anomaly is followed in late fall/early winter by a large NAO-like signal [90, 91], primarily resulting from eastern subpolar SST forcing [99]. By explicitly modeling the SST anomaly decay and assuming again a 2-month response time, Frankignoul et al. [100] found that the NAO amplitude reached $45 \mathrm{~m} / 0.45 \mathrm{~K}$ at $500 \mathrm{hPa}$, broadly consistent with [22].

Several studies investigated the influence of the latitudinal variability of the Gulf Stream (GS) front. An index with seasonal temporal resolution of the position of the GS north wall in 1979-2009 was used to show that a southward excursion of the GS front was followed a year later in winter by a storm track extension to the east [101] and, for small excursions, a negative NAO-like signal, with indication (in view of the limited sample) of large amplitude and strong non-linearity when the GS shifts far from its climatological value [65]. However, based on the same GS index, Joyce et al. [102] found that a southward GS shift leads by only 3 months enhanced Greenland blocking and a southward shift of the storm track over the Labrador Sea. They speculated that these changes may be linked to broader changes in the Atlantic Meridional Overturning Circulation (although synchronous SST variations were not explored) and also noted that the lag correlation was very different before the 1970s. It is noteworthy that Minobe and Maeda [103] suggested that the Gulf Stream migrates on multidecadal timescale in accordance with the Atlantic Multidecadal Oscillation (their Fig. 7). Wills et al. [94] used daily resolution during winter 1979-2013 to estimate the atmospheric response to the GS variability, as represented by the averaged SST in a broad GS region, finding that a low above the GS and a barotropic wavetrain extending 
toward Europe and western Russia lags a positive SST anomaly by several weeks. The response seems primarily driven by anomalous vertical motion northeast of the GS path, but its amplitude is limited (about $23 \mathrm{~m} / \mathrm{K}$ at $500 \mathrm{hPa}$ ).

In summary, large-scale SST anomalies and western boundary current frontal variability seem to drive a strong atmospheric response in the cold season, with evidence of asymmetry and nonstationarity. Larger atmospheric signals are not expected in higher resolution reanalyses, which are strongly constrained by observations, but higher oceanic resolution might lead to a more accurate assessment of their link with frontal variability and oceanic mesoscale structures.

\section{Comparison With the Simulated Response of AGCMs to Prescribed Extra-Tropical SST Anomalies}

Early response studies with low-resolution AGCMs found small responses to (broad) extra-tropical SST anomalies, on the order of $20 \mathrm{~m}$ per K at $500 \mathrm{hPa}$ [2]. Similarly, Peings and Magnusdottir [104] found at $1^{\circ}$ resolution a limited response to the Atlantic Multidecadal Oscillation (about $20 \mathrm{~m}$ at $500 \mathrm{hPa} / 1$ $\mathrm{K})$ and [105] a small response to SST in a broad region along the subarctic frontal zone ( $40 \mathrm{~m}$ at $300 \mathrm{hPa} / 3-4 \mathrm{~K}$ ). Smirnov et al. [14] found that the (symmetric) cold season response to a meridional shift of the $\mathrm{OE}$ was much larger at $1 / 4^{\circ}$ than at $1^{\circ}$ resolution, but still smaller in magnitude and different in spatial structure compared with the NPO response estimated from observations and discussed in the "Observational Estimates of the Response of the Atmosphere to SST Anomalies" section. In an attempt to provide a direct comparison between simulated and "observed" responses, we have focused on the OE region for which it was possible to find observational and modeling studies using consistent SST indices (in all the studies used in this figure - see the figure caption for details - the spatial pattern of the SST anomaly is qualitatively similar to that seen in Fig. 4). For compactness, the responses at upper levels are expressed in $\mathrm{m} / \mathrm{K}$ and only the magnitude of the responses are compared in Fig. 5, not the sign or the actual pattern (the magnitude of the anomalies in geopotential height and SST are given separately in the figure caption). One first notices in this figure that the "observed" responses are larger than the simulated ones as all the points fall above the $y=x$ line (black dashed line). The highresolution study by Smirnov et al. [14] shows the highest response magnitude but the latter is still about a factor of two smaller than the observational estimate by Frankignoul et al. [20]. The other interesting feature of this figure is the wide spread in the "observed" responses, from about 20 to 100 $\mathrm{m} / \mathrm{K}$. This emphasizes that although observational studies assess the statistical significance of a lagged relationship between SST and atmospheric variables, as well as, in more recent studies, the local significance of an atmospheric response (see the black lines in Fig. 4, right column), none to our knowledge has attempted to estimate an errorbar on the magnitude of the atmospheric response (nor have we in Fig. 5).

It must also be emphasized that while we have highlighted that smaller magnitudes are generally obtained with AGCMs compared with observational estimates, a few studies have reported more comparable responses. For example, a strongly
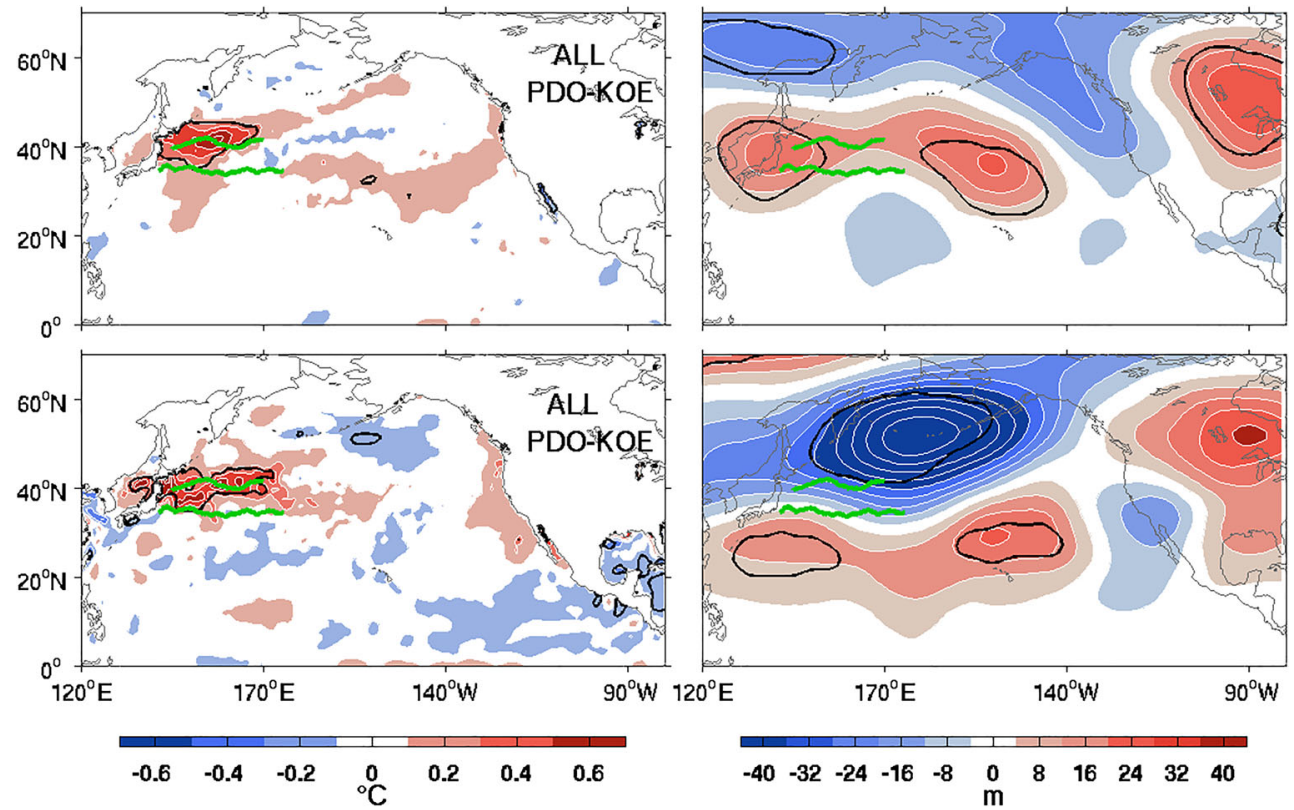

Fig. 4 The estimated response of the atmosphere (right column, geopotential height anomaly at $300 \mathrm{hPa}$, in $\mathrm{m}, \mathrm{CI}=8 \mathrm{~m}$ ) to a northward shift of the OE (left column, SST anomaly in $\mathrm{K}, \mathrm{CI}=0.2 \mathrm{~K}$ ) in the ERAinterim reanalysis (1979-2014). The early (October-NovemberDecember, top row) and late (February-March-April, bottom row) winter

atmospheric responses are shown (the SST anomaly is shown 2 months earlier). The green curves (left panels) indicate the mean position of the $\mathrm{OE}$ and $\mathrm{KE}$ fronts and the black contours in all panels indicate the $10 \%$ significance level. Figure adapted from [22]. ()American Meteorological Society. Used with permission 


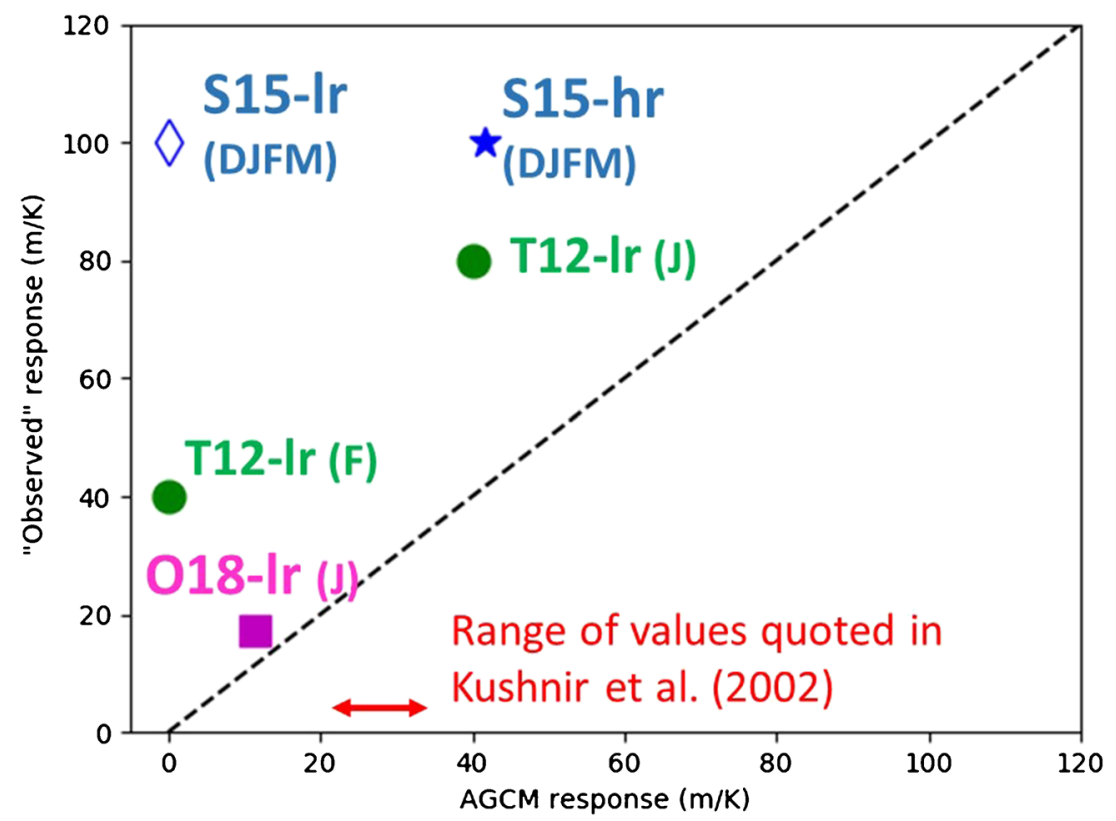

Fig. 5 A comparison of "observed" and simulated atmospheric response to a northward shift of the Oyashio extension. The responses are for the winter season and upper levels (the letter in parenthesis indicates the GCM month considered) and, for compactness, are expressed as geopotential height anomaly per degree SST anomaly $(\mathrm{m} / \mathrm{K})$. The studies were chosen as follows: $\mathrm{S} 15$ at $300 \mathrm{hPa}([14] ; 50 \mathrm{~m} / 1.2 \mathrm{~K}$ and 0 $\mathrm{m} / 1.2 \mathrm{~K}$ for high and low resolution, respectively) compared with [20] at $250 \mathrm{hPa}(45 \mathrm{~m} / 0.45 \mathrm{~K}$ to account for seasonal enhancement); T12 [21]

asymmetric and, in addition, nonlinear remote response to a meridional GS shift was found by Seo et al. [65] with a regional model at 40-km resolution, showing a high sensitivity to SST forcing (in the weakest SST anomaly case considered, the response exceeds $20 \mathrm{~m}$ at $250 \mathrm{hPa}$ for a strikingly small $0.4 / 9=$ $0.04 \mathrm{~K} \mathrm{SST}$ anomaly-see their Fig. 4i). In rather highresolution (T213) simulations, Zhou et al. [106] found a large winter response to the extra-tropical PDO, reaching about -75 $\mathrm{m}$ at $500 \mathrm{hPa}(-6.6 \mathrm{hPa}$ for SLP)/0.7 K SST, when the daily global SST variability during 1981-1990 was included in the background, slightly smaller amplitude when the daily SSTs were only prescribed in the North Pacific, and no significant response in their absence or at lower resolution, suggesting that the small SST scales enhance the response to SST anomalies. However, the response was very weak with the 1991-2000 SST background, emphasizing its nonstationarity [107].

There is very little theoretical guidance beyond the arguments summarized in the "How Do the Extra-Tropical Oceans Affect the Storm Track/Jet Stream System?" section to explain this diversity of results. One attractive paradigm, reminiscent of earlier ideas by Shutts [108] and Peng and Robinson [109], is that as the resolution of an AGCM increases, the diabatic heating/cooling generated by an SST anomaly and its interaction with weather systems becomes nearly balanced by eddy heat transports (lateral and vertical). This was, for example, seen in the study by Smirnov et al. [14] compared with itself as it presented both observed and modeled responses at $250 \mathrm{hPa}(60 \mathrm{~m} / 0.75 \mathrm{~K}$ in January, $30 \mathrm{~m} / 0.75 \mathrm{~K}$ in February for the observations, and $40 \mathrm{~m} / 1 \mathrm{~K}$ and $0 \mathrm{~m} / 1 \mathrm{~K}$ for the coupled model in January and February respectively); $\mathrm{O} 18$ ( [105], $40 \mathrm{~m} / 3.5 \mathrm{~K}$ ) compared at $300 \mathrm{hPa}$ with [95] $200 \mathrm{hPa}(12 \mathrm{~m} / 0.7 \mathrm{~K})$. The subscript "lr" and "hr" indicate low- and high-resolution (i.e., horizontal grid size smaller or larger than $100 \mathrm{~km}$ ). The range of model responses quoted in [2] is given as a reference in red

when moving from low to high resolution. In this limit, the response of the large-scale flow to an SST anomaly becomes closer to the "thermally equilibrated" mode of the AGCM, as the apparent heat source balancing the large-scale flow nearly vanishes. This dynamics leads to a weak anomalous surface heat flux $\left(\mathrm{F}^{\prime}\right)$ and circulation over the SST anomaly because of the nature of the thermally equilibrated mode. In the opposite limit, possibly more likely to occur in a low-res AGCM, eddies come less efficiently into equilibrium with the diabatic heating and stronger $\mathrm{F}^{\prime}$ and surface circulation occur.

Alternatively, it might be that the differences in AGCMs' responses reflect the different history of natural variability experienced by the model atmospheres while being forced by the same SST anomaly. The study by Deser et al. [110] clearly illustrates how even $\sim 100$-year-long records do not fully constrain the response of the extra-tropical atmosphere to ENSO events owing to its large natural variability. It is possible that a similar effect is at work here, different AGCMs sampling preferentially different regions of the atmospheric phase space, even though their time mean might be in agreement with observations. If this view is correct, the nonlinearity and nonstationarity of some of the responses reported above should be taken with caution. As should then the more basic results from studies where the sampling of the atmospheric phase space is limited (e.g., only one winter in [16]). 


\section{Implications for Climate Change Predictions}

The response of the midlatitude atmospheric circulation to anthropogenic forcing over the twenty-first century has been traditionally described as a tug of war between enhanced equator-to-pole temperature gradient at upper levels and reduced gradient at lower levels in the Northern Hemisphere (e.g., [111, 112]). Conversely, in the Southern Hemisphere, it has been viewed within the context of a competition between the impact of $\mathrm{CO}_{2}$ forcing vs stratospheric ozone recovery (e.g., [113]). In addition, the global increase in moisture content of the atmosphere with increasing surface temperature results in a larger role of the moist dynamics discussed in the "How Do the Extra-Tropical Oceans Affect the Storm Track/ Jet Stream System?" section (e.g., [114]). In either Hemisphere, the role of the midlatitude oceans has only so far been discussed and demonstrated in relation to largescale aspects of the oceanic circulation: retarding surface warming in the Southern Ocean (as a result of upwelling of cold deep water, e.g., [111, 115]) and weakening of the upper circulation and associated poleward heat transport in the North Atlantic (e.g., [116]).

Analysis of instrumental records over the twentieth century has suggested an enhanced surface warming over all western boundary currents compared with the global mean ocean [117]. This has been observed in AR5 models too, except for the Gulf Stream where models predict a weakening of the upper circulation $[118,119]$. It is not clear at this stage if this pattern of future warming is robust, especially considering the large biases in the representation of the ocean circulation, western boundary currents, and their separation from the coast in coarse climate models. Indeed, recent studies [120, 121] have shown that very different SST responses develop in the Atlantic in response to increasing $\mathrm{CO}_{2}$ concentrations as oceanic resolution increases. A similar behavior is suggested for the western North Pacific in Fig. 6.

Could these changes compete with the above-mentioned effects of equator-to-pole temperature gradients on the Jet Stream in the twenty-first century? A direct investigation of the impact of these SST changes in current high-resolution coupled simulations has not yet, to our knowledge, been conducted. Nevertheless, two lines of research offer some perspective in the North Atlantic basin. First, serendipitously, a proxy for the expected warming of the western boundary currents in this region is provided by the SST bias produced in most coupled models with oceanic resolution on the order of $25 \mathrm{~km}$ or coarser as a result of an inaccurate Gulf Stream separation ${ }^{8}$. The impact of this bias has been recently studied by Lee et al. [122] in the UK Met Office Unified Model during

\footnotetext{
${ }^{8}$ A possible caveat here is that in the high-res experiments mentioned in the previous paragraph, not only is the ocean near the East coast of the US warming, but so does the land [121]. This does not occur in [122].
}

the cold season (about $60 \mathrm{~km}$ resolution in the atmosphere in midlatitudes). They showed that it induces a wavetrain across the Northern Hemisphere, with a positive geopotential height anomaly above the warm SST bias and a negative one over Iceland at $500 \mathrm{hPa}$ (their Fig. 3e).

In addition, although the effect seen in [122] was rather weak (about $20 \mathrm{~m}$ at $500 \mathrm{hPa}$ for a $\sim 5 \mathrm{~K} \mathrm{SST}$ anomaly), it is consistent with independent findings reported in the context of the observed and simulated decadal climate variability seen in the North Atlantic in wintertime. Indeed, both Sato et al. [56] and Siqueira and Kirtman [123] have shown a qualitatively similar wavetrain emanating from the Gulf Stream region in response to a surface warming on the North flank of the separated Gulf Stream. The anomalies suggested in the latter study are very significant as they are low-pass filtered (decadal timescale) and reach a magnitude of $30 \mathrm{~m}$ at $200 \mathrm{hPa}$ for a 1-K SST anomaly (their Fig. 3b, e). It is also significant that such signals were simulated in the high res, but not the low res, version of the coupled model used in their study. The impact of warmer SST anomalies north of the separated Gulf Stream on the strength of the Icelandic Low, although with a different sign, was highlighted in earlier studies of decadal variability in the Atlantic in long instrumental records (e.g., $[124,125])^{9}$. The dynamics is certainly complex, as studies using high-resolution reanalysis dataset (ERA5, with $25 \mathrm{~km}$ resolution) have emphasized the presence of tropospheric mesoscale signals set by the Gulf Stream warm core [127], in addition to the non-linear effects suggested in some LAM studies (e.g., [65], see the "Comparison With the Simulated Response of AGCMs to Prescribed Extra-Tropical SST Anomalies" section).

In summary, uncertainties associated with the magnitude and structure of the atmospheric response in AGCMs (the "Observational Constraints on the Extra-Tropical Oceanic Forcing" section) warrant caution but the suggestion from recent studies with coupled models and AGCMs with an horizontal resolution on the order of $50 \mathrm{~km}$, as well as the decadal variability seen in the instrumental records, is that midlatitude air-sea interactions associated with a warming of the western boundary currents will be an important factor setting the pattern of Jet Stream/storm track change in the twenty-first century.

\section{Conclusion}

This review has provided a snapshot of the state of the research at a very productive period, as many high-res simulations prepared for the 6th assessment report of the IPCC are beginning to be analyzed [128]. A whole spectrum of studies

\footnotetext{
${ }^{9}$ A similar impact of decadal changes in the Kuroshio extension on the observed Jet Stream has been suggested by [126] in the North Pacific.
} 

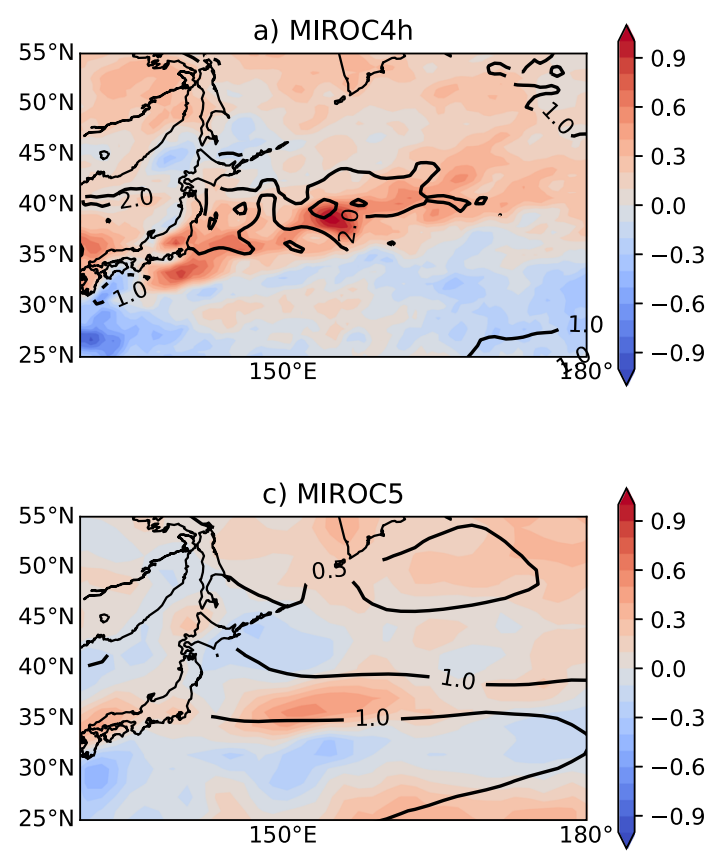

Fig. 6 Rain rate difference (in units of $\mathrm{mm} /$ day, color) between the first and the last 20 years (2016-2035 minus 1969-1950) of the historicalfuture (RCP4.5) simulation of MIROC4h (a), MIROC-ESM (b), and MIROC5 (c), along with SST differences in contours (in K). One observes a more localized and stronger SST and rainfall change in the higher

has been discussed. Some emphasize the role of atmospheric resolution in setting different dynamical responses to largescale SST anomalies and in hopefully converging to an accurate response of the atmosphere to an oceanic forcing on the scale of the atmospheric deformation radius $(\sim 1000 \mathrm{~km})$. Some studies, on the other hand, emphasize the impact of smaller spatial scales in the SST field on extra-tropical cyclones and, through as yet not fully understood mechanisms, on the storm track/Jet Stream system. This, we distinguished from the former forcing, as occurring on the scale of the oceanic deformation radius $(10-100 \mathrm{~km})$. We now tentatively attempt to answer the question raised in the title of this review.

First, we expect that further analysis of the new generation of coupled models will confirm the presence of stronger atmospheric responses to changes in extra-tropical SST anomalies, more in line with observational estimates. In addition, we expect that more variability simulated for the twenty-first century will be initiated at the oceanic deformation radius scale $(10-100 \mathrm{~km})$ where oceanic motions in the form of mesoscale eddies, quasi-permanent fronts, meandering, and shifts of the western boundary currents are strongest. Early studies investigating the response of the upper ocean circulation and SST field to increasing greenhouse gas concentrations have already demonstrated a large sensitivity to resolution, with previously unseen signals emerging in the highest resolution coupled models (the "Implications for Climate Change Predictions" section). Thus, we expect more surprises coming from the extra-tropical oceans to be unveiled, in addition to the

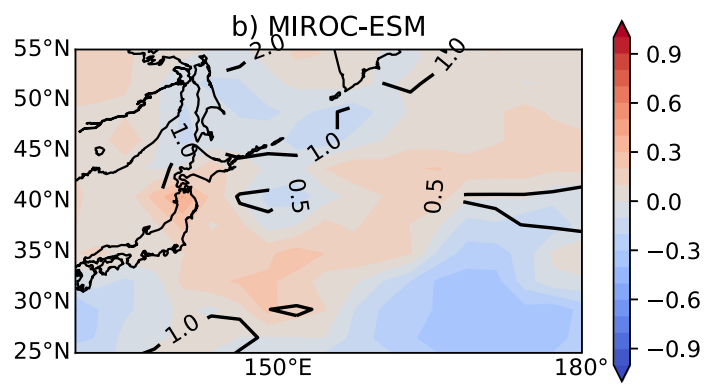

resolution model (MIROC4h, $60 \mathrm{~km}$ atmosphere and eddy permitting ocean) compared with the other two (atmospheric resolution of $1.4^{\circ}$ and $2.8^{\circ}$ for MIROC5 and MIROC5-ESM, respectively). Figure courtesy of S. Minobe

predicted weakening of the thermohaline circulation of the North Atlantic.

While the recent research provides more optimism for a source of predictability from the ocean than was available at the time of the review by Kushnir et al. [2], several outstanding issues remain:

Robustness Across Models The review by Kushnir et al. [2] emphasized that, although the remote response of a given AGCM to an extra-tropical SST anomaly might be significant, one cannot expect it to be reproduced by another AGCM. The limited number of studies currently available is such that there is no evidence yet to support or invalidate this conclusion for high-resolution models. To solve this problem, coordinated experiments should be conducted using high-resolution models $[129,130]$. A promising example is HighResMIP [128] in which historical and future AGCM as well as coupled GCM experiments are conducted both with high-resolution and low-resolution models. Thus, how atmospheric responses to the ocean depend on resolution can be investigated systematically across models for the first time. In particular, HighREsMIP's optional experiment using SST smoothing will provide an opportunity to examine the robustness of recently reported findings based on single model experiments at high resolution. We have reviewed several mechanisms and diagnostics which could help in understanding model differences (e.g., thermal equilibration and surface heat flux anomaly at equilibrium, atmospheric noise, thermal damping at 
fronts and anomalous horizontal surface heat flux gradient, production of low PV air masses, eddy kinetic energy thresholds). Our suggestion is to encourage readers to analyze what aspects of midlatitude air-sea interactions are robust across models and what aspects are not, and to test these mechanisms and apply these diagnostics to understand why. Data from the HighResMIP project is already beginning to be available for such effort (e.g., see Fig. 1).

Model Set-Ups For future coordinated experiments, we would like to suggest three different lines of research:

1. Slab experiments (or 1D mixed layer models) in which the mean SST pattern is controlled but which would allow a feedback of the atmosphere on the ocean. The motivation is that the atmospheric response to SST anomalies might overestimate the coupling on short time scale in AMIP style experiments because of this missing feedback and also underestimate or misrepresent the long term oceanic forcing [131].

2. Convection permitting experiments as some mechanisms such as CSI need grid-spacing finer than $25 \mathrm{~km}$ and might suffer from the parameterization of convection. Only a limited area model is possible here due to computational constraints but the domain needs to be sufficiently large to minimize the impact of lateral boundary conditions on the response to SST anomaly. The protocol should impose a given domain, initial and boundary conditions. The limitation of those experiments is that they would not include the feedback on the atmospheric mean state.

3. Global high-resolution AGCMs run in idealized geometries, stepping the complexity up bit by bit (i.e., building on what has been done for low-resolution AGCMs by Brayshaw et al. [68]).

Observational Benchmarks Model responses need to be tested against some observational counterparts. Unfortunately, empirical estimates of the magnitude of the observed response of the atmosphere to extra-tropical SST anomalies currently lack errorbars. The example given in Fig. 5 for the OE highlights the spread expected from different statistical methods, choice of time lag, and the subjectivity in putting a number on maps like those displayed in Fig. 4. Here again a coordinated project aiming at comparing the various methods and at constructing an objective metric is very much encouraged and needed.

Regional Differences The different continental geometries of the Northern and Southern Hemispheres may lead to differences in the dominant mechanism(s) of oceanic influence. For example, the North Atlantic western boundary is perfectly shaped for land sea temperature contrast and Gulf Stream induced SST contrasts to add constructively during the cold season, highlighting the likely importance of frontal circulations in this problem. Such dynamics is less clear for the Kuroshio region because of the buffering effect of the Sea of Japan and also less clear for the Agulhas region in the Southern Ocean where land sea contrasts are much weaker. A thorough comparison of the atmospheric response with SST anomalies in these regions would likely be insightful and could be tackled both using observations and global AGCM at high resolution.

This review has only focused on the Northern Hemisphere during the cold season because this is where, historically, most of the efforts of the community have been concentrated. Likewise, we have omitted discussing radiative and cloud effects. This choice was made to limit and focus this review but more and more research suggests that important signals from the oceans emerge in the summer season (e.g., [132]), and that the radiative effect of clouds on the storm track/Jet Stream system is significant (e.g., [133]). Conversely, few studies have investigated the role of ocean-atmosphere interactions at higher Southern latitudes, despite much research on the dynamics of the Antarctic Circumpolar Current. It is not clear that the dynamics highlighted in the "How Do the ExtraTropical Oceans Affect the Storm Track/Jet Stream System?" section will be relevant there, as SSTs are generally lower and diabatic heating effects in storms are much weaker there [134].

A recent surprise in ocean modeling might be worth mentioning as a final thought. In a study with a high-res ocean model (about 7-km resolution), Renault et al. [135] found that, surprisingly, rather than increasing the resolution further to resolve the submesoscale dynamics $(\sim 1 \mathrm{~km})$, adding a more realistic representation of the air-sea exchange of momentum on the scale of the oceanic eddies (10-100 km) improved the representation of western boundary current dynamics very significantly. Strikingly, the "missing physics" is actually well enough understood [136] that it can be parameterized for ocean-only or coupled integrations with a low-res atmospheric model. We wonder whether such "parameterisable missing physical processes" exist in the context of the oceanic forcing of the storm track/Jet Stream system. And if they do, whether they might soon be revealed, thereby alleviating the challenging and unsatisfactory prospect of ever increasing model resolution ${ }^{10}$. The slanted nature of convection in midlatitudes, which is not represented at all in any low-res $\mathrm{AGCMs}^{11}$ although it can be parameterized (e.g., [53]), comes to mind as it allows a nearly local isentropic connection between upper tropospheric levels and the underlying sea surface [137]. It is

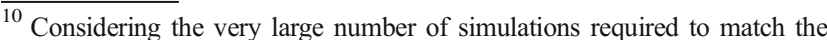
demands of large ensemble (to separate signals from noise), multiple scenarios (to account for policy decisions) and multiple models (to account for model uncertainties), this is not even a practical strategy.

${ }^{11}$ Because of weak frontal circulations and the fact that model physics tests only stability to vertical displacements of air parcels.
} 
hoped that further work with the CMIP6 ensemble including HighResMIP [128] and the latest reanalysis datasets such as ERA5, as well as the development of new theories, will answer this question.

Acknowledgments The authors would like to thank the Grantham Institute at Imperial College London for sponsoring a workshop on the topic of this review on 25-26 February 2019. Feedbacks on an earlier version of this manuscript by Ralf Toumi, Brian Hoskins, Justin Small, and Mike Byrne were also greatly appreciated, as are discussions with Yochanan Kushnir and Richard Seager during a short visit of the lead author to Lamont. Careful reading and comments by two anonymous reviewers, as well as the Editor Isla Simpson, greatly helped to improve this review. We thank the EU H2020 project PRIMAVERA for sharing the model data used in Fig. 1. SM is supported by the Japan Society for the Promotion of Science (JSPS) KAKENHI Grant numbers 19H05704 and $18 \mathrm{H} 04129$.

\section{Compliance with Ethical Standards}

Conflict of Interest On behalf of all authors, the corresponding author states that there is no conflict of interest.

Open Access This article is distributed under the terms of the Creative Commons Attribution 4.0 International License (http:// creativecommons.org/licenses/by/4.0/), which permits unrestricted use, distribution, and reproduction in any medium, provided you give appropriate credit to the original author(s) and the source, provide a link to the Creative Commons license, and indicate if changes were made.

\section{References}

Papers of particular interest, published recently, have been highlighted as:

- Of importance

•- Of major importance

1. Frankignoul C. Sea surface temperature anomalies, planetary waves, and air-sea feedback in the middle latitudes. Reviews of Geophysics. 1985;23:357.

2. Kushnir Y, Robinson WA, Bladé I, Hall NMJ, Peng S, Sutton R. Atmospheric GCM response to extratropical SST anomalies: synthesis and evaluation*. Journal of Climate. 2002;15:2233-56.

3. Robinson WA. Review of WETS - the workshop on extratropical SST anomalies. Bulletin of the American Meteorological Society. 2000;81(3):567-77.

4. Kwon Y-O, Alexander MA, Bond NA, Frankignoul C, Nakamura H, Qiu B, et al. Role of the Gulf Stream and Kuroshio-Oyashio systems in large-scale atmosphere-ocean interaction: a review. Journal of Climate. 2010;23:3249-81.

5. IPCC, 2013: Climate change 2013: the physical science basis. Contribution of working group I to the fifth assessment report of the intergovernmental panel on climate change [Stocker, T.F., D. Qin, G.K. Plattner, M. Tignor, S.K. Allen, J. Boschung, A. Nauels, Y. Xia, V. Bex and P.M. Midgley (eds.)]. Cambridge University Press, Cambridge, United Kingdom and New York, NY, USA, 1535 pp.

6. Feldstein SB. The dynamics of NAO teleconnection pattern growth and decay. Quarterly Journal of the Royal Meteorological Society. 2003;129:901-24.
7. Scaife AA, Arribas A, Blockley E, Brookshaw A, Clark RT, Dunstone N, et al. Skillful long-range prediction of European and North American winters. Geophysical Research Letters. 2014;41:2514-9.

8. Dunstone N, Smith D, Scaife A, Hermanson L, Eade R, Robinson $\mathrm{N}$, et al. Skilful predictions of the winter North Atlantic Oscillation one year ahead. Nature Geoscience. 2016;9:809-14.

9. Baker LH, Shaffrey LC, Sutton RT, Weisheimer A, Scaife AA. An intercomparison of skill and overconfidence/underconfidence of the wintertime North Atlantic Oscillation in multimodel seasonal forecasts. Geophysical Research Letters. 2018;45:7808-17.

10. Simpson IR, Deser C, Mckinnon KA, Barnes EA. Modeled and observed multidecadal variability in the North Atlantic jet stream and its connection to sea surface temperatures. Journal of Climate. 2018;31:8313-38.

11. Small R, De Szoeke S, Xie S, O'Neill L, Seo H, Song Q, et al. Airsea interaction over ocean fronts and eddies. Dynamics of Atmospheres and Oceans. 2008;45(3-4):274-319.

12. Feliks Y, Ghil M, Simonnet E. Low-frequency variability in the midlatitude atmosphere induced by an oceanic thermal front. Journal of the Atmospheric Sciences. 2004;61:961-81.

13. Minobe S, Kuwano-Yoshida A, Komori N, Xie S-P, Small RJ. Influence of the Gulf Stream on the troposphere. Nature. 2008:452:206-9.

14. Smirnov D, Newman M, Alexander MA, Kwon Y-O, Frankignoul C. Investigating the local atmospheric response to a realistic shift in the Oyashio sea surface temperature front. Journal of Climate. 2015;28:1126-47.

15. Ma X, Chang P, Saravanan R, Montuoro R, Hsieh J-S, Wu D, et al. Distant influence of Kuroshio eddies on North Pacific weather patterns? Scientific Reports. 2015;5.

16. Ma X, Chang P, Saravanan R, Montuoro R, Nakamura H, Wu D, et al. Importance of resolving Kuroshio front and eddy influence in simulating the North Pacific storm track. Journal of Climate. 2017;30:1861-80.

17. Parfitt R, Czaja A, Minobe S, Kuwano-Yoshida A. The atmospheric frontal response to SST perturbations in the Gulf Stream region. Geophysical Research Letters. 2016;43(5):2299-306.

18. Sheldon L, Czaja A, Vannière B, Morcrette C, Sohet B, Casado M, et al. A 'warm path' for Gulf Stream-troposphere interactions. Tellus A: Dynamic Meteorology and Oceanography. 2017;69: 1299397.

19. Foussard A, Lapeyre G, Plougonven R. Storm track response to oceanic eddies in idealized atmospheric simulations. Journal of Climate. 2019;32(2):445-63.

20. Frankignoul C, Sennéchael N, Kwon Y-O, Alexander MA. Influence of the meridional shifts of the Kuroshio and the Oyashio extensions on the atmospheric circulation. Journal of Climate. 2011;24:762-77.

21. Taguchi B, Nakamura H, Nonaka M, Komori N, Kuwano-Yoshida A, Takaya K, et al. Seasonal evolutions of atmospheric response to decadal SST anomalies in the North Pacific subarctic frontal zone: observations and a coupled model simulation. Journal of Climate. 2012;25:111-39.

22. Révelard A, Frankignoul C, Kwon Y-O. A multivariate estimate of the cold season atmospheric response to North Pacific SST variability. Journal of Climate. 2018;31(7):2771-96.

23. Emanuel KA. The Lagrangian parcel dynamics of moist symmetric instability. Journal of the Atmospheric Sciences. 1983;40: 2368-76.

24. Craig GC, Selz T. Mesoscale dynamical regimes in the midlatitudes. Geophysical Research Letters. 2018;45:410-7.

25. Fox-Kemper B, Adcroft A, Böning CW, Chassignet EP, Curchitser E, Danabasoglu G, et al. Challenges and prospects in ocean circulation models. Frontiers in Marine Science. 2019;6. 
26. Jung T, Miller MJ, Palmer TN, Towers P, Wedi N, Achuthavarier D. ... \& Marx, L. High-resolution global climate simulations with the ECMWF model in Project Athena: experimental design, model climate, and seasonal forecast skill. Journal of Climate. 2018;25(9):3155-72.

27. Schiemann R, Demory ME, Shaffrey LC, Strachan J, Vidale PL, Mizielinski MS. ... \& Jung, T. The resolution sensitivity of Northern Hemisphere blocking in four 25-km atmospheric global circulation models. Journal of Climate. 2017;30(1):337-58.

28. Dawson A, Palmer TN, Corti S. Simulating regime structures in weather and climate prediction models. Geophysical Research Letters. 2012;39(21).

29. Skamarock WC. Evaluating mesoscale NWP models using kinetic energy spectra. Monthly weather review. 2004;132(12):3019-32.

30. Skamarock WC, Park SH, Klemp JB, Snyder C. Atmospheric kinetic energy spectra from global high-resolution nonhydrostatic simulations. Journal of the Atmospheric Sciences. 2014;71(11): 4369-81.

31. Klaver R, Haarsma R, Vidale PL, Hazeleger W. Effective resolution in high resolution global atmospheric models for climate studies. Atmospheric Science Letters. in revision.

32. Hoskins BJ, James IN, White GH. The shape, propagation and mean-flow interaction of large-scale weather systems. Journal of the atmospheric sciences. 1983;40(7):1595-612.

33. Held IM, Phillipps PJ. Sensitivity of the eddy momentum flux to meridional resolution in atmospheric GCMs. Journal of climate. 1993;6(3):499-507.

34. Orlanski, I. The rationale for why climate models should adequately resolve the mesoscale. 2008; In High resolution numerical modelling of the atmosphere and ocean (pp. 29-44). Springer, New York, NY.

35. Willison J, Robinson WA, Lackmann GM. The importance of resolving mesoscale latent heating in the North Atlantic storm track. Journal of the Atmospheric Sciences. 2013;70(7):2234-50.

36. Peng S, Mysak LA, Derome J, Ritchie H, Dugas B. The differences between early and midwinter atmospheric responses to sea surface temperature anomalies in the northwest Atlantic. Journal of Climate. 1995;8(2):137-57.

37. Peng S, Robinson WA, Hoerling MP. The modeled atmospheric response to midlatitude SST anomalies and its dependence on background circulation states. Journal of Climate. 1997;10(5): 971-87.

38. Vannière B, Demory ME, Vidale PL, Schiemann R, Roberts MJ, Roberts CD, et al. Multi-model evaluation of the sensitivity of the global energy budget and hydrological cycle to resolution. Climate Dynamics. 2018;52(11):6817-46.

39. Hoskins BJ, Draghici I, Davies HC. A new look at the $\omega$-equation. Quarterly Journal of the Royal Meteorological Society. 1978;104(439):31-8.

40. Catto JL, Shaffrey LC, Hodges KI. Can climate models capture the structure of extratropical cyclones? Journal of Climate. 2010;23(7):1621-35.

41. O'Neill LW, Haack T, Chelton DB, Skyllingstad E. The Gulf Stream convergence zone in the time-mean winds. Journal of the Atmospheric Sciences. 2017;74(7):2383-412.

42. Parfitt R, Czaja A. On the contribution of synoptic transients to the mean atmospheric state in the Gulf Stream region. Quarterly Journal of the Royal Meteorological Society. 2016;142:1554-61.

43. Hoskins BJ. The role of potential vorticity in symmetric stability and instability. Quarterly Journal of the Royal Meteorological Society. 1974;100(425):480-2.

44. Bennetts DA, Hoskins BJ. Conditional symmetric instability-a possible explanation for frontal rainbands. Quarterly Journal of the Royal Meteorological Society. 1979;105(446):945-62.
45. Emanuel KA. On assessing local conditional symmetric instability from atmospheric soundings. Monthly weather review. 1983;111(10):2016-33.

46. Emanuel, K. A. Conditional symmetric instability: a theory for rainbands within extratropical cyclones. In Mesoscale meteorology - theories, observations and models (pp. 231-245). Springer. Dordrecht. 1983.

47. Schultz DM, Schumacher PN. The use and misuse of conditional symmetric instability. Monthly Weather Review. 1999;127(12): 2709-32.

48. Czaja A, Blunt N. A new mechanism for ocean-atmosphere coupling in midlatitudes. Quarterly Journal of the Royal Meteorological Society. 2011;137(657):1095-101.

49. Glinton MR, Gray SL, Chagnon JM, Morcrette CJ. Modulation of precipitation by conditional symmetric instability release. Atmospheric Research. 2017;185:186-201.

50. Lean HW, Clark PA. The effects of changing resolution on mesocale modelling of line convection and slantwise circulations in FASTEX IOP16. Quarterly Journal of the Royal Meteorological Society. 2003;129(592):2255-78.

51. Thorpe, A. J. Parameterisation of mesoscale processes. Proc. seminar on physical parameterisation for numerical models of the atmosphere. 1986; ECMWF, Shinfield Park, Reading, UK, $205-$ 233.

52. Nordeng TE. The effect of vertical and slantwise convection on the simulation of polar lows. Tellus A. 1987;39(4):354-75.

53. Lindstrom SS, Nordeng TE. Parameterized slantwise convection in a numerical model. Monthly weather review. 1992;120(5):74256.

54. Scaife et al., Does increased atmospheric resolution improve seasonal climate predictions? Atm. Sci. Let., in press.

55. Hoskins BJ, Karoly DJ. The steady linear response of a spherical atmosphere to thermal and orographic forcing. Journal of the Atmospheric Sciences. 1981;38(6):1179-96.

56. Sato K, Inoue J, Watanabe M. Influence of the Gulf Stream on the Barents Sea ice retreat and Eurasian coldness during early winter. Environmental Research Letters. 2014;9(8):084009.

57. Watanabe M, Kimoto M. Atmosphere-ocean thermal coupling in the North Atlantic: a positive feedback. Quarterly Journal of the Royal Meteorological Society. 2000;126(570):3343-69.

58. O'Reilly CH, Minobe S, Kuwano-Yoshida A, Woollings T. The Gulf Stream influence on wintertime North Atlantic jet variability. Quarterly Journal of the Royal Meteorological Society. 2016;143(702):173-83.

59. O'Reilly CH, Minobe S, Kuwano-Yoshida A. The influence of the Gulf Stream on wintertime European blocking. Climate Dynamics. 2015;47(5-6):1545-67.

60. Small RJ, Tomas RA, Bryan FO. Storm track response to ocean fronts in a global high-resolution climate model. Climate Dynamics. 2013;43(3-4):805-28.

61. Piazza M, Terray L, Boé J, Maisonnave E, Sanchez-Gomez E. Influence of small-scale North Atlantic sea surface temperature patterns on the marine boundary layer and free troposphere: a study using the atmospheric ARPEGE model. Climate Dynamics. 2015;46(5-6):1699-717.

62. Whitaker JS, Sardeshmukh PD. A linear theory of extratropical synoptic eddy statistics. Journal of the Atmospheric Sciences. 1998;55(2):237-58.

63. Peng S, Whitaker JS. Mechanisms determining the atmospheric response to midlatitude SST anomalies. Journal of climate. 1999;12(5):1393-408.

64. Seo H, Kwon Y-O, Joyce TM, Ummenhofer CC. On the predominant nonlinear response of the extratropical atmosphere to meridional shifts of the Gulf Stream. Journal of Climate. 2017;30(23): 9679-702. 
65. Seo H, Kwon Y-O, Park J-J. On the effect of the East/Japan Sea SST variability on the North Pacific atmospheric circulation in a regional climate model. Journal of Geophysical Research: Atmospheres. 2014;119(2):418-44.

66. Nakamura H, Sampe T, Tanimoto Y, Shimpo A. Observed associations among storm tracks, jet streams and midlatitude oceanic fronts. Earth's Climate Geophysical Monograph Series. 2004: 329-46.

67. Nakamura H, Sampe T, Goto A, Ohfuchi W, Xie S-P. On the importance of midlatitude oceanic frontal zones for the mean state and dominant variability in the tropospheric circulation. Geophysical Research Letters. 2008;35(15).

68. Brayshaw DJ, Hoskins B, Blackburn M. The storm-track response to idealized SST perturbations in an aquaplanet GCM. Journal of the Atmospheric Sciences. 2008;65(9):2842-60.

69. Vannière B, Czaja A, Dacre H, Woollings T. A "cold path" for the gulf stream-troposphere connection. Journal of Climate. 2017;30(4):1363-79.

70. Omrani N-E, Ogawa F, Nakamura H, Keenlyside N, Lubis SW, Matthes K. Key Role of the Ocean Western Boundary currents in shaping the Northern Hemisphere climate. Scientific Reports. 2019;9(1).

71. Hoskins BJ, Valdes PJ. On the existence of storm-tracks. Journal of the Atmospheric Sciences. 1990;47(15):1854-64.

72. Small RJ, Msadek R, Kwon Y-O, Booth JF, Zarzycki C. Atmosphere surface storm track response to resolved ocean mesoscale in two sets of global climate model experiments. Climate Dynamics. 2018;52(3-4):2067-89.

73. Kuwano-Yoshida A, Minobe S. Storm-track response to SST fronts in the Northwestern Pacific Region in an AGCM. Journal of Climate. 2017;30(3):1081-102.

74. Papritz L, Spengler T. Analysis of the slope of isentropic surfaces and its tendencies over the North Atlantic. Quarterly Journal of the Royal Meteorological Society. 2015;141(693):3226-38.

75. Tamarin T, Kaspi Y. Mechanisms controlling the downstream poleward deflection of midlatitude storm tracks. Journal of the Atmospheric Sciences. 2017;74(2):553-72.

76. Doyle JD, Warner TT. The impact of the sea surface temperature resolution on mesoscale coastal processes during GALE IOP 2. Monthly Weather Review. 1993;121(2):313-34.

77. Reed RJ, Grell GA, Kuo Y-H. The ERICA IOP 5 storm. Part II: sensitivity tests and further diagnosis based on model output. Monthly Weather Review. 1993;121(6):1595-612.

78. Chang SW, Holt TR, Sashegyi KD. A numerical study of the ERICA IOP 4 marine cyclone. Monthly Weather Review. 1996;124(1):27-46.

79. Giordani H, Caniaux G. Sensitivity of cyclogenesis to sea surface temperature in the Northwestern Atlantic. Monthly Weather Review. 2001;129(6):1273-95.

80. Minobe S, Miyashita M, Kuwano-Yoshida A, Tokinaga H, Xie SP. Atmospheric response to the Gulf Stream: seasonal variations*. Journal of Climate. 2010;23:3699-719.

81. Boer AMD, Collier AB, Caballero R. Processes driving thunderstorms over the Agulhas Current. Journal of Geophysical Research: Atmospheres. 2013;118:2220-8.

82. Palmer T. Climate forecasting: build high-resolution global climate models. Nature. 2014;515(7527):338-9.

83. Voosen P. The earth machine. Science. 2018;361(6400):344-7.

84. Neumann P, Düben P, Adamidis P, Bauer P, Brück M, Kornblueh $\mathrm{L}$, et al. Assessing the scales in numerical weather and climate predictions: will exascale be the rescue? Philosophical Transactions of the Royal Society A: Mathematical. Physical and Engineering Sciences. 2019;377(2142):20180148.

85. Catto JL, Jakob C, Berry G, Nicholls N. Relating global precipitation to atmospheric fronts. Geophysical Research Letters. 2012;39(10)
86. Parfitt R, Czaja A, Kwon Y-O. The impact of SST resolution change in the ERA-Interim reanalysis on wintertime Gulf Stream frontal air-sea interaction. Geophysical Research Letters. 2017;44(7):3246-54.

87. Pfahl S, Schwierz C, Croci-Maspoli M, Grams CM, Wernli H. Importance of latent heat release in ascending air streams for atmospheric blocking. Nature Geoscience. 2015;8(8):610-4.

88. Ratcliffe RAS, Murray R. New lag associations between North Atlantic sea temperature and European pressure applied to longrange weather forecasting. Quarterly Journal of the Royal Meteorological Society. 1970;96:226-46.

89. Palmer TN, Sun Z. A modelling and observational study of the relationship between sea surface temperature in the north-west Atlantic and the atmospheric general circulation. Quarterly Journal of the Royal Meteorological Society. 1985;111:947-75.

90. Czaja A, Frankignoul C. Influence of the North Atlantic SST on the atmospheric circulation. Geophysical Research Letters. 1999;26:2969-72.

91. Czaja A, Frankignoul C. Observed impact of Atlantic SST anomalies on the North Atlantic Oscillation. Journal of Climate. 2002; $15: 606-23$.

92. Reynolds RW, Smith TM, Liu C, Chelton DB, Casey KS, Schlax MG. Daily high-resolution-blended analyses for sea surface temperature. Journal of Climate. 2007;20:5473-96.

93. Masunaga R, Nakamura H, Miyasaka T, Nishii K, Tanimoto Y. Separation of climatological imprints of the Kuroshio extension and Oyashio fronts on the wintertime atmospheric boundary layer: their sensitivity to SST resolution prescribed for atmospheric reanalysis. Journal of Climate. 2015;28:1764-87.

94. Wills SM, Thompson DWJ, Ciasto LM. On the observed relationships between variability in Gulf Stream sea surface temperatures and the atmospheric circulation over the North Atlantic. Journal of Climate. 2016;29:3719-30.

95. Wills SM, Thompson DWJ. On the observed relationships between wintertime variability in Kuroshio-Oyashio extension sea surface temperatures and the atmospheric circulation over the North Pacific. Journal of Climate. 2018;31:4669-81.

96. Deser C, Tomas RA, Peng S. The transient atmospheric circulation response to North Atlantic SST and sea ice anomalies. Journal of Climate. 2007;20:4751-67.

97. Révelard A, Frankignoul C, Sennéchael N, Kwon Y-O, Qiu B. Influence of the decadal variability of the Kuroshio extension on the atmospheric circulation in the cold season. Journal of Climate. 2016;29:2123-44.

98. Nakamura H, Nishina A, Minobe S. Response of storm tracks to bimodal Kuroshio path states south of Japan. Journal of Climate. 2012;25(21):7772-9.

99. Gastineau G, Frankignoul C. Influence of the North Atlantic SST variability on the atmospheric circulation during the twentieth century. Journal of Climate. 2015;28:1396-416.

100. Frankignoul C, Chouaib N, Liu Z. Estimating the observed atmospheric response to SST anomalies: maximum covariance analysis, generalized equilibrium feedback assessment, and maximum response estimation. Journal of Climate. 2011;24:2523-39.

101. Kwon Y-O, Joyce TM. Northern hemisphere winter atmospheric transient eddy heat fluxes and the Gulf Stream and KuroshioOyashio extension variability. Journal of Climate. 2013;26: 9839-59.

102. Joyce TM, Kwon YO, Seo H, Ummenhofer CC. Meridional Gulf Stream shifts can influence wintertime variability in the North Atlantic storm track and Greenland blocking. Geophysical Research Letters. 2019;46(3):1702-8.

103. Minobe $\mathrm{S}$, Maeda A. A $1^{\circ}$ monthly gridded sea-surface temperature dataset compiled from ICOADS from 1850 to 2002 and Northern Hemisphere frontal variability. International Journal of Climatology. 2005;25(7):881-94. 
104. Peings Y., and G. Magnusdottir. Wintertime atmospheric response to Atlantic multidecadal variability: effect of stratospheric representation and ocean-atmosphere coupling. Climate Dynamics. 2016; 47:1029.

105. Okajima S, Nakamura H, Nishii K, Miyasaka T, Kuwano-Yoshida A, Taguchi B, et al. Mechanisms for the maintenance of the wintertime basin-scale atmospheric response to decadal SST variability in the North Pacific subarctic frontal zone. Journal of Climate. 2018;31(1):297-315.

106. Zhou G, Latif M, Greatbatch RJ, Park W. Atmospheric response to the North Pacific enabled by daily sea surface temperature variability. Geophys. Res. Lett. 2015;42:7732-9.

107. Zhou G, Latif M, Greatbatch RJ, Park W. State dependence of atmospheric response to extratropical North Pacific SST anomalies. Journal of Climate. 2017;30:509-25. https://doi.org/10.1175/ jcli-d-15-0672.1

108. Shutts GJ. Some comments on the concept of thermal forcing. Quarterly Journal of the Royal Meteorological Society. 2007;113:1387-94. https://doi.org/10.1002/qj.49711347817.

109. Peng S, Robinson WA. Relationships between atmospheric internal variability and the responses to an extratropical SST anomaly. Journal of Climate. 2001;14:2943-59. https://doi.org/10.1175/ 1520-0442(2001)014<2943:rbaiva>2.0.co;2.

110. Deser C, Simpson IR, Mckinnon KA, Phillips AS. The Northern Hemisphere extratropical atmospheric circulation response to ENSO: how well do we know it and how do we evaluate models accordingly? Journal of Climate. 2017;30:5059-82.

111. Held I. Large scale dynamics and global warming. Bull. Am. Met. Soc. 1993;74(2):228-42.

112. Shaw TA, Baldwin M, Barnes EA, Caballero R, Garfinkel CI, Hwang Y-T, et al. Storm track processes and the opposing influences of climate change. Nature Geoscience. 2016;9:656-64. https://doi.org/10.1038/ngeo2783.

113. Thompson DWJ, Solomon S, Kushner PJ, England MH, Grise KM, Karoly DJ. Signatures of the Antarctic ozone hole in Southern Hemisphere surface climate change. Nature Geoscience. 2011;4:741-9. https://doi.org/10.1038/ngeo1296.

114. O'Gorman PA, Merlis TM, Singh MS. Increase in the skewness of extratropical vertical velocities with climate warming: fully nonlinear simulations versus moist baroclinic instability. Quarterly Journal of the Royal Meteorological Society. 2017;144:208-17. https://doi.org/10.1002/qj.3195.

115. Marshall J, Armour KC, Scott JR, Kostov Y, Hausmann U, Ferreira D, et al. The ocean's role in polar climate change: asymmetric Arctic and Antarctic responses to greenhouse gas and ozone forcing. Philosophical Transactions of the Royal Society A: Mathematical, Physical and Engineering Sciences 2014;372: 20130040-. doi:10.1098/rsta.2013.0040.

116. Woollings, T., Gregory, J. M., Pinto, J. G., Reyers, M. and Brayshaw, D. J.: Response of the North Atlantic storm track to climate change shaped by ocean-atmosphere coupling. Nature Geoscience, 2012; 5 (5). pp. 313317. ISSN 17520894 doi: https://doi.org/10.1038/ngeo1438

117. Wu L, Cai W, Zhang L, Nakamura H, Timmermann A, Joyce T, et al. Enhanced warming over the global subtropical western boundary currents. Nature Climate Change. 2012;2:161-6. https://doi.org/10.1038/nclimate1353.

118. Yang H, Lohmann G, Wei W, Dima M, Ionita M, Liu J. Intensification and poleward shift of subtropical western boundary currents in a warming climate. Journal of Geophysical Research: Oceans. 2016;121:4928-45. https://doi.org/10.1002/2015jc011513.

119. Seager R, Simpson IR. Western boundary currents and climate change. Journal of Geophysical Research: Oceans. 2016;121: 7212-4. https://doi.org/10.1002/2016jc012156.

120. Saba VS, Griffies SM, Anderson WG, Winton M, Alexander MA, Delworth TL, et al. Enhanced warming of the Northwest Atlantic
Ocean under climate change. Journal of Geophysical Research: Oceans. 2016;121:118-32. https://doi.org/10.1002/2015jc011346.

121. Small, J. 2019; in prep.

122. Lee RW, Woollings TJ, Hoskins BJ, Williams KD, O'Reilly CH, Masato G. Impact of Gulf Stream SST biases on the global atmospheric circulation. Climate Dynamics. 2018;51:3369-87. https:// doi.org/10.1007/s00382-018-4083-9.

123. Siqueira L, Kirtman BP. Atlantic near-term climate variability and the role of a resolved Gulf Stream. Geophysical Research Letters. 2016;43:3964-72. https://doi.org/10.1002/2016g1068694.

124. Deser C, Blackmon ML. Surface climate variations over the North Atlantic Ocean during winter: 1900-1989. Journal of Climate. 1993;6:1743-53. https://doi.org/10.1175/1520-0442(1993) $006<1743$ :scvotn $>2.0$. co $; 2$.

125. Czaja A, Marshall J. Observations of atmosphere-ocean coupling in the North Atlantic. Quarterly Journal of the Royal Meteorological Society. 2001;127:1893-916. https://doi.org/10. 1002/qj.49712757603.

126. O'Reilly CH, Czaja A. The response of the Pacific storm track and atmospheric circulation to Kuroshio Extension variability. Quarterly Journal of the Royal Meteorological Society. 2014;141:52-66. https://doi.org/10.1002/qj.2334.

127. Cobb A, Czaja A. Mesoscale signature of the North Atlantic Oscillation and its interaction with the ocean. Geophysical Research Letters. 2019. https://doi.org/10.1029/2018gl080744.

128. Haarsma RJ, Roberts MJ, Vidale PL, Senior CA, Bellucci A, Bao Q, et al. High resolution model intercomparison project (HighResMIP v1.0) for CMIP6. Geoscientific Model Development. 2016;9:4185208. https://doi.org/10.5194/gmd-9-4185-2016.

129. Roberts MJ, Vidale PL, Senior C, Hewitt HT, Bates C, Berthou S, et al. The benefits of global high resolution for climate simulation: process understanding and the enabling of stakeholder decisions at the regional scale. Bulletin of the American Meteorological Society. 2018;99:2341-59.

130. Robinson W, Speich S, Chassignet E. Exploring the interplay between ocean eddies and the atmosphere. Eos. 2018;99.

131. Sutton R, Mathieu P-P. Response of the atmosphere-ocean mixedlayer system to anomalous ocean heat-flux convergence. Quarterly Journal of the Royal Meteorological Society. 2002;128:1259-75.

132. Ossó A, Sutton R, Shaffrey L, Dong B. Observational evidence of European summer weather patterns predictable from spring. Proceedings of the National Academy of Sciences. 2017;115: 59-63. https://doi.org/10.1073/pnas.1713146114.

133. Ceppi P, Hwang Y-T, Frierson DMW, Hartmann DL. Southern Hemisphere jet latitude biases in CMIP5 models linked to shortwave cloud forcing. Geophysical Research Letters. 2012;39. https://doi.org/10.1029/2012gl053115.

134. Hoskins BJ, Hodges KI. A new perspective on Southern Hemisphere storm tracks. Journal of Climate. 2005;18:4108-29. https://doi.org/10.1175/jcli3570.1.

135. Renault L, Marchesiello P, Masson S, Mcwilliams JC. Remarkable control of western boundary currents by eddy killing, a mechanical air-sea coupling process. Geophysical Research Letters. 2019;46: 2743-51. https://doi.org/10.1029/2018gl081211.

136. Gaube P, Chelton DB, Samelson RM, Schlax MG, O'Neill LW. Satellite observations of mesoscale eddy-induced Ekman pumping. Journal of Physical Oceanography. 2015;45:104-32. https://doi.org/10.1175/jpo-d-14-0032.1.

137. Hewitt HT, Bell MJ, Chassignet EP, Czaja A, Ferreira D, Griffies SM, et al. Will high-resolution global ocean models benefit coupled predictions on short-range to climate timescales? Ocean Modelling. 2017;120:120-36. https://doi.org/10.1016/j.ocemod.2017.11.002.

Publisher's Note Springer Nature remains neutral with regard to jurisdictional claims in published maps and institutional affiliations. 